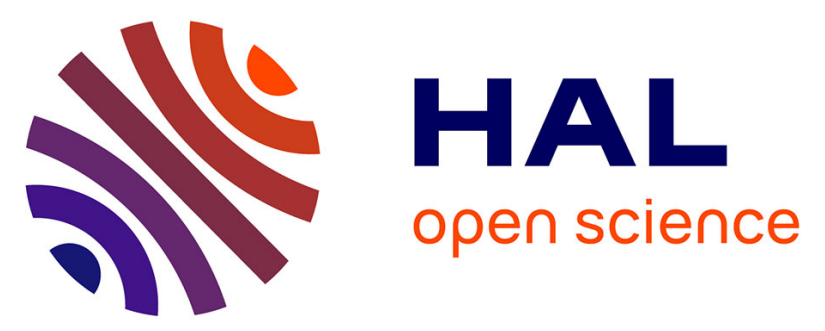

\title{
Combined meso-scale modeling and experimental investigation of the effect of mechanical damage on the transport properties of cementitious composites
}

Balaji Raghavan, Davood Niknezhad, Fabrice Bernard, Siham Kamali-Bernard

\section{- To cite this version:}

Balaji Raghavan, Davood Niknezhad, Fabrice Bernard, Siham Kamali-Bernard. Combined mesoscale modeling and experimental investigation of the effect of mechanical damage on the transport properties of cementitious composites. Journal of Physics and Chemistry of Solids, 2016, 96-97, pp.2237. 10.1016/j.jpcs.2016.04.013 . hal-01309703

\section{HAL Id: hal-01309703 https://hal.science/hal-01309703}

Submitted on 21 Jun 2016

HAL is a multi-disciplinary open access archive for the deposit and dissemination of scientific research documents, whether they are published or not. The documents may come from teaching and research institutions in France or abroad, or from public or private research centers.
L'archive ouverte pluridisciplinaire HAL, est destinée au dépôt et à la diffusion de documents scientifiques de niveau recherche, publiés ou non, émanant des établissements d'enseignement et de recherche français ou étrangers, des laboratoires publics ou privés. 


\title{
Combined meso-scale modeling and experimental investigation of the effect of mechanical damage on the transport properties of cementitious composites
}

\author{
Balaji Raghavan ${ }^{1}$,Davood Niknezhad ${ }^{1}$, Fabrice Bernard $^{1}$, Siham \\ Kamali-Bernard ${ }^{1, *}$ \\ ${ }^{1}$ Laboratoire de Genie Civil et Genie Mecanique, INSA Rennes, 20 Avenue des Buttes de \\ Coesmes, Rennes 35078, France
}

\begin{abstract}
The transport properties of cementitious composites such as concrete are important indicators of their durability, and are known to be heavily influenced by mechanical loading. In the current work, we use meso-scale hygro-mechanical modeling with a morphological 3D two phase mortar-aggregate model, in conjunction with experimentally obtained properties, to investigate the coupling between mechanical loading and damage and the permeability of the composite. The increase in permeability of a cylindrical test specimen at $28 \%$ aggregate fraction during a uniaxial displacement-controlled compression test at $85 \%$ of the peak load was measured using a gas permeameter. The mortar's mechanical behavior is assumed to follow the well-known compression damaged plasticity (CDP) model with isotropic damage, at varying thresholds, and obtained from different envelope curves. The damaged intrinsic permeability of the mortar evolves according to a logarithmic matching law with progressive loading. We fit the matching law parameters to the experimental result for the test specimen by inverse identification using our meso-scale model. We then subject a series of virtual composite specimens to quasi-static uniaxial compressive loading with varying boundary conditions to obtain the simulated damage and strain evolutions, and use the damage data and the previously identified parameters to
\end{abstract}

\footnotetext{
${ }^{1}$ corresponding author siham.kamali-bernard@insa-rennes.fr
} 
determine the evolution of the macroscopic permeability tensor for the specimens, using a network model. We conduct a full parameter study by varying aggregate volume fraction, granulometric distribution, loading/boundary conditions and "matching law" parameters, as well as for different strain-damage thresholds and uniaxial loading envelope curves. Based on this study, we propose Avrami equation-based upper and lower bounds for the evolution of the damaged permeability of the composite.

Keywords: D. Fracture; D. Mechanical properties; D. Microstructure; D.

Physical properties

\section{Introduction}

It is now common knowledge that the transport properties of a cementitious composite, i.e; permeability and chloride diffusion coefficient, are important indicators of its durability. These composites are porous and basic, and the characteristics of its pore network, dimensions and interconnectivity of the capillarity porosity determine the transfer of aggressive species inside the matrix $[1,2]$. A perusal of the available literature on the subject reveals myriad studies, mostly experimental, on the different factors influencing the permeability and diffusivity of the undamaged composite, for example, mix parameters, moisture content and environmental conditions such as sulphate attack [3]. As a general rule of thumb, a reduction in volume, size, and inter-connection of pores will reduce the permeability and diffusivity. A reduction in pore characteristics can be achieved by selecting appropriate aggregates or cement paste properties. Reducing the amount of water relative to the cementitious material used can lead to improved pore formation. However, while the transport properties of the undamaged composite are associated with the overall porosity and the size/stability of the voids in it, the transport properties of the same composite material under load, i.e. damaged concrete depends heavily on the cracks present. The formation and propagation of cracks in such composite structures is one of the major factors influencing the transport properties and thus 
their durability. Cracks accelerate the penetration of water and the diffusion of harmful ions, such as chloride, leading to damage and durability problems [10]. Therefore, predicting the behavior of the damaged composite using only the data for the undamaged material is pointless and there is a clear need to study the evolution of transport properties in cementitious composites with stressinduced damage.

The relationship between the mechanical properties and the permeability of cementitious composites has been under investigation over the last few decades. Choinska et al [4] investigated the coupled problem of mechanical damage in concrete and its permeability and concluded that for low to intermediate levels of stress, the permeability appears to increase drastically as the load approaches the ultimate compressive strength (UCS) of the material. Samaha et al [5] confirmed the presence of micro-cracks during uniaxial compression loading up to about $70 \%$ of the UCS, but found that the transport properties were largely unaffected. In this phase, the composite showed 15 to $20 \%$ less resistance to fluid and ion movement. Picandet et al [6] found that a load of $90 \%$ of the UCS created an inter-connected network of micro-cracks which increased the gas permeability of concrete even after complete unloading. The permeability measured to chlorides follows the same behavior for the loads over than of $80 \%$ [7] or $90 \%$ of the peak [8]. The repeat of a compression load between 60 and $80 \%$ leads to an increase in the permeability as well by extension of micro-cracking. One may conclude that the interconnection of the generated micro-cracks during mechanical loading appears to be the driving factor for changes in the transport properties of a cementitious composite. Picandet et al [9] experimentally studied the effect of a crack on the gas and water permeability of cementitious composites and found that both gas and water permeability increased proportionally to the cube of the crack opening displacement. Djerbi Tegguer et al [10] performed a single cycle of compressive loading for various loads between $60 \%$ and $90 \%$ of the UCS. They reported that the damaged permeability increased by a factor of 10 for an increase in damage by a factor of 2.5. They also noted that gas permeability was more sensitive to damage levels 
than the chloride diffusivity, a result that can be confirmed by [1].

The literature clearly corroborates the experimental observation that damage, in other words, the creation and propagation of micro or macro-cracks, leads to an increase in the value of the transport properties of a cementitious material. However, studying the effect of progressive damage on the permeability during continuous loading of a composite specimen experimentally, in the same manner as [10], is no easy task, requiring a great amount of time and incurring significant cost. This is where simulation-based investigation could potentially make a difference, as once sufficiently accurate material models have been established for the phenomena under consideration, and using the greatly advanced numerical tools available today, one would greatly limit the time, effort and money involved in a full-bore experimental investigation.

In addition to the above experimental studies, there have been simulation-based studies on the damage-permeability coupling in cement-based materials [11]. Chatzigeorgiou et al [12] used a discrete lattice model to obtain this coupling. However, most of the modeling investigations typically relate the intrinsic damaged permeability with strain and isotropic damage for a homogeneous material and do not take the heterogeneity of the composite into account, with the exception of the meso-macro multi-scale approach used by Jourdain et al [13] who considered a single crack in a homogenized domain, by solving the macroscopic moisture transport equation. There is, in our opinion, a dearth of literature on modeling-based investigation that couples local damage (distributed throughout the domain) and strain data with permeability for a cementitious i.e.heterogeneous composite with multiple phases, under progressive load.

Cementitious composites are typically heterogeneous brittle materials that are known to fracture through the formation, growth and coalescence of microcracks [14]. Failure processes in concrete depend on the loading rate and are significantly influenced by micro-inertia of the material adjacent to a propagating micro-crack and moisture in the capillary pores.

These phenomena demonstrate the involvement of multiple length scales at different levels in the mechanical response [15] as well as transport behavior of 
the composite. The smallest length scale is associated with the microstructure (cement paste) composed of water, hydrates (mainly C-S-H, Portlandite CH or Ettringite [16]) and anhydrous cement grains. The meso-scale is divided into a sub-meso-scale where the mortar is considered to be constituted by sand particles embedded in a homogeneous cement paste, and a meso-scale itself representing concrete as a two or three phase composite material (mortar matrix and aggregates with or without an Interfacial Transition Zone or ITZ [17]).

A realistic numerical simulation of material behavior must adequately represent the influence of as many of these length scales as possible on the mechanical and hygral response. Purely macroscopic models that do not consider the mesoscale or microstructural interactions miss out on critical information on local variables (like damage and strain) that renders them nearly useless in problems related to durability. Lattice models have been successfully used $[18,19]$ but the results obtained appear to be lattice geometry-dependent. On the other hand, mesoscopic modeling with a regularized continuum description using a multi-phase composite model along with matrix-inclusions interaction, in conjunction with a regularized model for the bulk material, is a safe and effective approach for characterizing the effects of the different length scales on the composite's mechanical and transport behaviors. These models provide a good balance of low computational effort and sufficient reliability. The recently contributed exact solutions in $[20,21]$ for general heterogenous materials and by Barretta et al $[22,23]$ for Functionally Graded Materials (FGMs) could be useful for comparison with $\mathrm{FE}$ computations on the type of composites considered here.

Since mesoscopic modeling of the composite is ostensibly the way to go, a sufficiently detailed morphological model for the mortar-aggregate composite is the next step. The mortar phase may be described as a partially saturated open porous medium with an isotropic permeability tensor under zero load. This tensor can dramatically change when load is applied due to the strain/damage dependence of the intrinsic permeability (as has been discussed in the earlier paragraphs of this section). As far as the aggregate phase is concerned, one needs to take into account their mineralogical nature, morphology, granulo- 
metric distribution and volume fraction. Depending on the type of aggregate (siliceous, plastic, calcareous) ergo texture (rough/smooth) [24] one can expect varying levels of bonding to the mortar phase [25], and have angular or rounded shapes [26], and of course volume fraction and gradation [27, 28, 29] all of which can significantly modify the stress distribution and thus the damage distribution within the mortar phase [30] and thus contribute to wildly varying transport parameters (e.g. permeability) of the whole composite.

The next aspect of the generation of meso-structures with random morphologies involves varying the shape, size distribution and volume fraction of the chosen aggregate particles. The literature shows $2 \mathrm{D}$ representations with circles/polygons [31, 15, 32], 3D analyses with spherical representations [25, 33, $30,34,26]$, realistic particles [35, 26, 36] and even considered the phenomenon of aggregate segregation due to elevated fluidity [26]. Finite Element mechanical analysis of the created mesostructures could use conforming/non-conforming meshes with tetrahedral [26] or cubic elements [37].

The mechanical constitutive behavior of the cement mortar (strain softening) for the selected shape, size and fraction of the aggregate particles with typedependent interaction between the phases is the next important aspect since this alone can cause significant variation in the results obtained. Depending on the type of loading, either brittle failure or viscoelastic rate-dependent models are typically used, with a few implementations focusing on quasi-static displacement controlled loadings where plastic behavior may be observed. An additional step involves selection of an appropriate strain-damage evolution curve. The purpose of this phase then is to determine the strain and damage distribution in the different phases of the composite under increasing/decreasing load.

The final, and equally critical phase of the meso-scale modeling, involves coupling the obtained mechanical response with the transport parameters. Network models do exist to calculate the permeability tensor for an undamaged composite $[38,26]$.

In the present publication, the authors combine an experimental investigation of the mechanical and transport properties with meso-scale mechanical-hygral 
modeling to investigate the coupling between the two physical phenomena for self-compacting concrete (SCC).

For the mechanical behavior under compressive loading, 3D FE analyses of quasi-static compression tests are performed for virtual composite specimens at different aggregate fractions using a rate-independent isotropic rate-independent plastic damage (CDP) continuum model for the mechanical behavior of the matrix (mortar) and an explicit morphological two-phase mesoscale model for the composite with a random spherical packing of spheres with different diameters (corresponding to the particular granulometric distribution and aggregate fraction), along with corresponding conforming FE meshes for the final composite. The experimental compression curve was fitted with an analytical elastoplastic envelope curve to obtain the damage evolution for the mortar phase under uniaxial compression with two different damage thresholds. mechanicalhygral coupling for the mortar phase was achieved using a logarithmic matching law. Finally a network model was used to compute the evolution of the damaged permeability tensor of the composite under progressive loading. This model was used in conjunction with the experimentally obtained damaged permeability for a composite at $28 \%$ aggregate fraction and the Simplex algorithm to iteratively identify the parameters of the matching law in the previous step. Finally, a complete parameter study has been conducted for various aggregate fractions and granulometric distributions, and obtain a set of bounding curves for the evolution of damaged permeability under progressive loading for the composite using the Avrami equation.

For the experimental portion, the gas permeability is determined for a sample of Self Consolidating Concrete with $28 \%$ aggregate volume fraction, made with Portland cement mixtures after one year of water curing, using both the sound as well as the damaged sample. Cracks were obtained by applying a uniaxial compressive load at $88 \%$ of the ultimate compressive strength over a two hour period. Damage is then experimentally determined by measuring the residual strain and the decrease in the elastic modulus, the latter being measured using an ultrasonic waves apparatus. 
The reason for loading our real and virtual composite specimens to more than $85 \%$ of the UCS of the concrete phase, albeit debatable, is corroborated by the observations of cracks in the concrete phase of several structures, both ancient and modern. In addition, the peak load in our work is identical to that considerd in the experimental investigation by Djerbi Tegguer et al [10].

The remainder of the paper is organized in the following manner: Section 2 details the experimental portion of our investigation, Section 3 explains the morphological three-phase composite model used to describe the multi-phase composite at the mesoscale. Section 4 explains the mechanical, hygral and mechano-hygral constitutive model used for the individual phases as well as the parameter-identification procedure, Section 5 lists and discusses the full set of results obtained after identification and simulation. The paper ends with concluding comments and suggestions for future work.

\section{Materials and Experimental Techniques}

\subsection{Materials and mixtures}

The mortar phase $[33,34]$ used in this work is composed of Portland cement CEM I 52.5 N (according to European standard EN 197-1), sand $S$ with grain size $0 / 4 \mathrm{~mm}$ and density $2600 \mathrm{~kg} / \mathrm{m}^{3}$, siliceous gravel with grain size $6.3 / 10$ $\mathrm{mm}$ and density $2660 \mathrm{~kg} / \mathrm{m}^{3}$, and a water to cement ratio $w / c=0.368$. Fluid Optima 224 based high range water reducer (HRWR) with density $1.05 \pm 0.02$ $\mathrm{gm} / \mathrm{cm}^{3}$ (at $20^{\circ} \mathrm{C}$ ) and $\mathrm{pH}: 4.70 \pm 1.00$ was used in order to enhance the flow ability of the mixtures (super-plasticizer). The overall composition is given in Table 1 .

The portland cement CEM I 52.5 N used has the mineralogical composition shown in Table 2.

\subsection{Mechanical loading}

A standard displacement-controlled uniaxial compression test was performed on a cylindrical specimen of mortar (figure 1) with dimensions $\phi 110 \times h 50 \mathrm{~mm}$ to 


\begin{tabular}{|l|c|}
\hline Constituent & $\mathrm{kg} / \mathrm{m}^{3}$ of fresh concrete \\
\hline \hline Cement CEM I 52.5 & 330 \\
\hline Sand $S(0-4)$ & 780 \\
\hline Aggregate & 760 \\
\hline Limestone powder & 240 \\
\hline Water & 210 \\
\hline Super-plasticizer (HRWR) & 2.8 \\
\hline
\end{tabular}

Table 1: Composition of the mixed concrete

\begin{tabular}{|c|c|c|c|c|c|c|c|}
\hline $\mathrm{CaO}$ & $\mathrm{SiO}_{2}$ & $\mathrm{Al}_{2} \mathrm{O}^{3}$ & $\mathrm{Fe}_{2} \mathrm{O}^{3}$ & $\mathrm{MgO}$ & $\mathrm{K}_{2} \mathrm{O}$ & $\mathrm{Na}_{2} \mathrm{O}$ & $\mathrm{SO}_{3}$ \\
\hline \hline $64.53 \%$ & $20.12 \%$ & $5.03 \%$ & $3.12 \%$ & $0.98 \%$ & $0.98 \%$ & $0.16 \%$ & $3.34 \%$ \\
\hline
\end{tabular}

Table 2: Mineralogical composition of the CEM I $52.5 \mathrm{~N}$ used in this study given in \% of weight content

first obtain the Ultimate Compressive Strength (UCS) of the mortar phase, and this was then used in conjunction with the CEB-FIP Model Code 2010 as well as the envelope curve proposed by [39] to plot the entire uniaxial compression curve and thus obtain the elastic constitutive and damage parameters for the mortar. This procedure allows us to avoid the usual problems associated with using the experimental compression test for the complete stress-strain curve.

The mechanical properties are shown in Table 3, ( $\rho$ =density, $Y=$ Young's modulus, $\mathrm{UCS}=$ Ultimate Compressive Strength, and $\nu=$ Poisson's ratio).

In order to induce internal damage in the specimens, repeated compressive

\begin{tabular}{|c|c|c|c|c|c|}
\hline Phase & $\rho\left(\mathrm{gm} / \mathrm{cm}^{3}\right)$ & UCS $(\mathrm{MPa})$ & $\mathrm{Y}(\mathrm{GPa})$ & $\nu$ & Permeability $\left(\mathrm{mm}^{-2}\right)$ \\
\hline \hline Mortar & 2.2 & 43.6 & 31.2 & 0.3 & $10^{-16}$ \\
\hline \hline
\end{tabular}

Table 3: Mechanical and transport properties of the mortar phase

loads were applied using a programmable load-controlled hydraulic press on cylindrical specimens of concrete at $28 \%$ aggregate volume fraction with dimensions $\phi 110 \times h 220 \mathrm{~mm}$. After 360 days of curing, the cylindrical specimens 
were loaded in uniaxial compression up to $35 \%, 60 \%$ and $88 \%$ of the UCS (measured after 1 year). Three cycles were used up to a load of $35 \%$ of the UCS for measuring the static modulus of elasticity $Y_{c}$. A single cycle was applied at $60 \%$ and $88 \%$ of the UCS and the $88 \%$ UCS load was sustained for different durations up to a period of 2 hours to allow for crack propagation. Loading and unloading were force (stress) controlled at $0.6 \mathrm{MPa} / \mathrm{s}$. The longitudinal strain in each cylinder was measured using an extensometer cell equipped with three linear variable displacement transducers (LVDT), with a range within $0.5 \mathrm{~mm}$ and an accuracy of $1 \mu \mathrm{m}$ (see figure 1). The transducers were laid over each $120^{\circ}$ interval to take into account any asymmetric longitudinal strain. These displacements were recorded during the loading and unloading phases until the recovery was negligible. The average longitudinal displacement was then calculated using the three LVDT measurements.

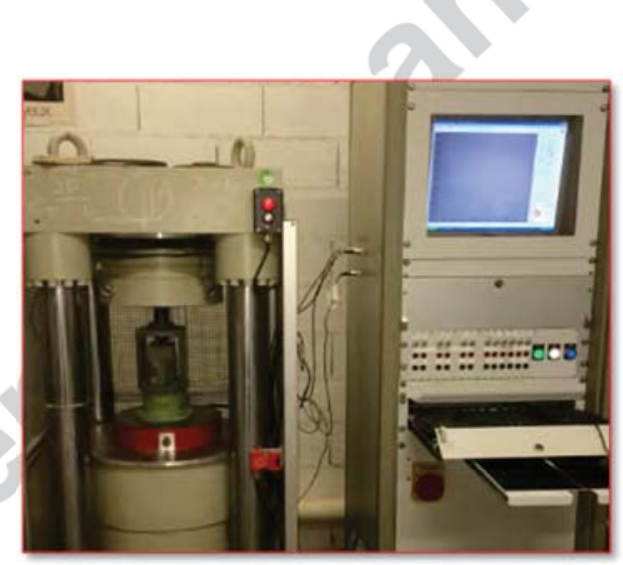

Figure 1: Experimental Set-up for the uniaxial compression test on $\phi 110 \times h 220 \mathrm{~mm}$ specimen of concrete at $28 \%$ aggregate volume fraction.

\subsection{Gas permeability measurement}

The gas used for the permeability measurement in this work is helium. The procedure used by the authors is identical to that used by Djerbi Tegguer et al in [10]. The apparent permeability was measured using a Cembureau constant 
head permeameter. Permeability measurements were made in an air-conditioned room $\left(20 \pm 2^{\circ} \mathrm{C}\right.$ and $\left.\mathrm{RH} 50 \pm 5 \%\right)$. Three concrete cylindrical samples of $50 \mathrm{~mm}$ thickness were cut from the central portion of the previous cylinders for testing and placed in a triaxial cell and injection pressure was applied below. The setup for performing gas permeability measurements was designed to work as a constant head permeameter under different gas pressures, with the possibility of changing the head value and measuring the gas inflow and outflow (Figure 2) $[40,41]$. Each disc was tested with five different pressures: 0.1, 0.2, 0.3, 0.4 and

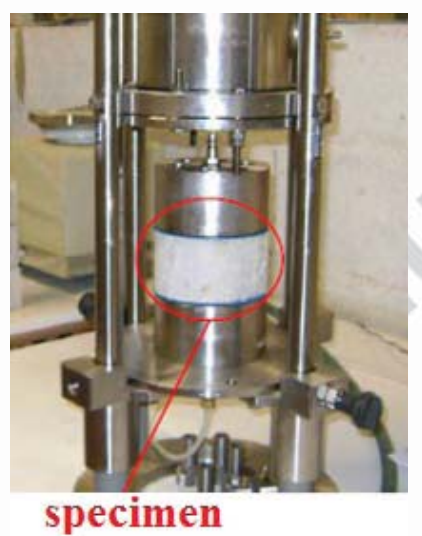

Figure 2: Experimental Set-up for the gas permeability measurement on $\phi 110 \times h 50 \mathrm{~mm}$ specimen of concrete at $28 \%$ aggregate volume fraction.

0.5 MPa. After initiating the percolation of helium through a specimen at a given applied pressure, sufficient time (ranging from 30 minutes to several hours) was provided to establish steady state flow before an actual measurement could be taken. This condition was verified by taking two measurements separated by a 15 min time interval. When the two values differed by less than $3 \%$, steady state flow was assumed. For each pressure differential, we calculated the apparent coefficient of permeability $K_{A}\left(\mathrm{~m}^{2}\right)$ using the Hagen-Poiseuille relationship for laminar flow of a compressible viscous fluid through a porous material:

$$
K_{A}=\frac{2 Q \mu L P_{a t m}}{A\left(P_{i}^{2}-P_{a t m}^{2}\right)}
$$


In order to determine the damaged intrinsic permeability $K_{i n t}$, we measured $K_{A}$ at different pressures and plot these against the inverse of the mean pressures $P_{m}=\left(P_{i}+P_{a t m}\right) / 2$. Using Klinkenberg's relationship:

$$
K_{\text {int }}=K_{\text {int }}\left(1+\frac{\beta}{P_{m}}\right)
$$

the ordinate-intercept of this plot yields the intrinsic permeability $K_{\text {int }}$.

\section{Morphological model of concrete at the mesoscale level}

An explicit morphological model was previously developed by the authors for representing concrete at the mesoscale, considering the concrete specimen as a two (or three-phase) composite material:

In this material the matrix phase consists of the cement mortar, while the inclusions phase consists of the aggregate grains, and the third (optional) phase is the interfacial transition zone (ITZ) for the cement paste, with a variety of contact conditions possible between the three phases. Full details on the model and techniques used are available in [26].

Using our previous work, we have used a random packing of spheres conforming
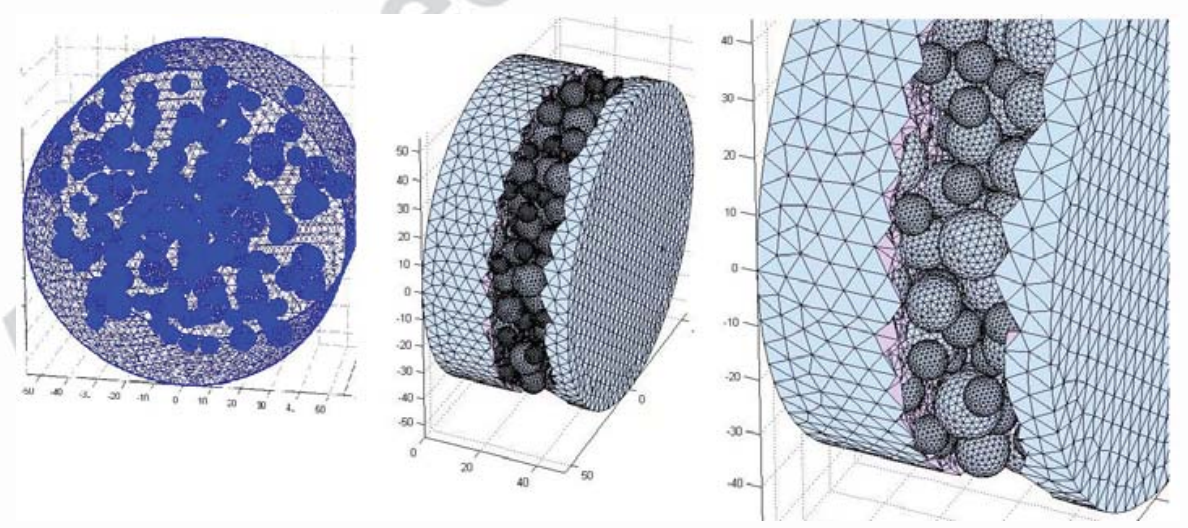

Figure 3: Typical 3D mesostructure and FE mesh with tetrahedral elements for virtual cylindrical specimen $\phi 110 \times 50 \mathrm{~mm}$ with spherical and polytopic aggregates 
to the experimental granulometric distribution of the composite specimen (table 4$)$ and volume fraction representing rounded aggregates ( $\tilde{D}$ represents the effective aggregate diameter). In addition, two different specimen geometries have been modeled, cubic and cylindrical. The typical FE meshes generated for the composite mesostructures for the two virtual specimens (with spherical aggregates) are shown in figure 3 .

All mesostructures have been obtained using the computational geometric

\begin{tabular}{|c|c|c|c|}
\hline Size range $(\mathrm{mm})$ & $\tilde{D}(\mathrm{~mm})$ & Weight $(\mathrm{g})$ & $V / V_{\text {total }}$ \\
\hline \hline$<12.5$ & 13 & 57 & 0.002 \\
\hline $10-12.5$ & 11.25 & 127 & 0.0935 \\
\hline $8-10$ & 9 & 127 & 0.1084 \\
\hline $5-8$ & 6.5 & 127 & 0.0742 \\
\hline$>5$ & 4 & 127 & 0.000279 \\
\hline
\end{tabular}

Table 4: Granulometric distribution of aggregates in concrete specimen

modeling algorithms described in detail in [26] and programmed in MATLAB $[42]$.

\section{Constitutive Models}

\subsection{Phase I: Mortar}

\subsubsection{Mechanical behavior}

The main task in failure description is the recognition of damage patterns. Concrete Damage Plasticity (CDP) is a popular constitutive model that was introduced by Kachanov [43] and further developed by Rabotnov[44] and Jankoviak et al [45]. the model has been used in this paper, as in the authors' previous work [26], for describing the elasto-plastic mechanical behavior of the mortar phase. This model uses the concept of isotropic damaged elasticity in combination with isotropic tensile and compressive plasticity to represent the inelastic behaviour of the mortar. 
In this model, the primary mode of failure in compressive loading is crushing while crack propagation is the primary mode of failure in tension, and the constitutive equation of mortar with scalar isotropic damage $d$ takes the following form:

$$
\sigma=(1-d) \mathbf{D}_{\mathbf{0}}:\left(\varepsilon-\varepsilon_{\mathbf{0}}\right)=(1-d) \bar{\sigma}
$$

where $\bar{\sigma}$ is the effective stress tensor. The Abaqus implementation uses a formulation intended to alleviate the mesh dependency of the results that can arise from strain localisation effects. This requires the explicit definition of a characteristic length based on the element geometry and associated with an integration point, as well as the definition of the post-peak tensile strength of the material as a function of the local cracking displacement.

The scalar (isotropic) damage variable $d\left(d=d_{t}\right.$ in tension and $d_{c}$ in com-

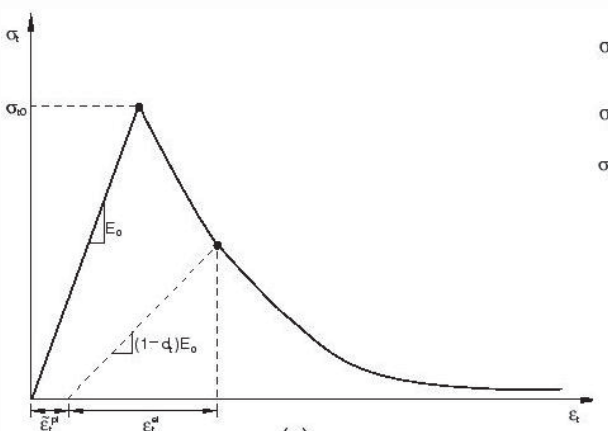

(a)

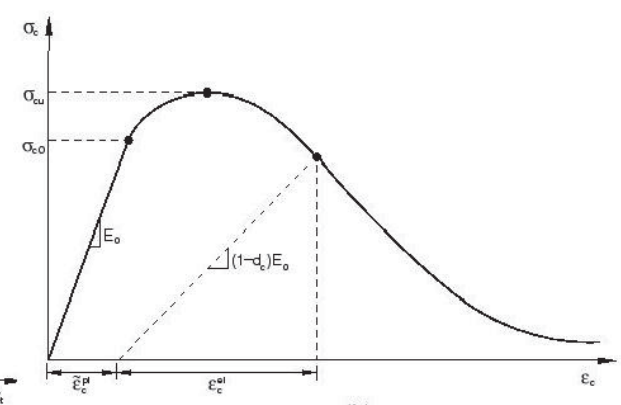

(b)

Figure 4: Constitutive Behavior of Cement Mortar under uniaxial (a) compressive (b) tensile loading.

pressive loading respectively) is related to the equivalent plastic strain and the effective stress tensor :

$$
d=d\left(\bar{\sigma}, \tilde{\varepsilon}^{p l}\right)
$$

Also, damage states in tension and compression are characterized independently by the equivalent plastic strains in tension and compression, $\tilde{\varepsilon}_{t}^{p l}$ and $\tilde{\varepsilon}_{c}^{p l}$ respec- 
tively. In terms of effective stresses, the yield function takes the form:

$$
F\left(\bar{\sigma}, \tilde{\varepsilon}^{p l}\right)=\frac{1}{1-\alpha}\left(\bar{q}-3 \alpha \bar{p}+\beta\left(\tilde{\varepsilon}^{p l}\right) \hat{\bar{\sigma}}_{\text {max }}+\gamma \hat{\bar{\sigma}}_{\text {max }}\right)-\bar{\sigma}_{c}\left(\tilde{\varepsilon}^{p l}\right)
$$

Failure via crack propagation (tension) and/or crushing (compression) is represented by increasing values of $\tilde{\varepsilon}_{t}^{p l}$ and $\tilde{\varepsilon}_{c}^{p l}$ respectively, which control the evolution of the yield surface as well as the degradation of the elastic stiffness of the mortar.

The concrete damaged plasticity model assumes nonassociated potential plastic flow. The fundamental group of the constitutive parameters consists of 4 values, which identify the shape of the flow potential surface and the yield surface. Considering the Drucker-Prager model for the flow function:

$$
G=\sqrt{\left(R_{c}-m R_{t} \tan \beta\right)^{2}+\bar{q}^{2}}-\bar{p} \tan \beta
$$

where $R_{t}$ and $R_{c}$ are the uniaxial tensile and compressive strengths of concrete respectively. $\beta$ is the dilation angle measured in the $p-q$ plane at high confining pressure, $m$ is an eccentricity of the plastic potential surface, $\bar{p}=-\frac{1}{3} \operatorname{trace}(\bar{\sigma})$ and $\bar{q}=\sqrt{\frac{3}{2}(\bar{\sigma}+\bar{p}):(\bar{\sigma}+\bar{p})}$.

Standard values of $\beta=35^{\circ}, m=0.1$ were assumed in this study. $R_{c}$ (i.e. the UCS of the mortar) was experimentally identified as described in the previous section. $R_{t}$ was determined from $R_{c}$ and the CEB-FIP relationship.

\subsubsection{Damage evolution with strain and strain-softening behavior}

Traditional damage modeling approaches assume either an onset of damage at the peak of the compression curve or an absence of plastic strains (i.e. pure elastic-damage models). Experimental research, both our own as well as that in the literature reviewed, clearly indicates the presence of micro-cracks in the mortar phase around $70-80 \%$ of the UCS $[5,10]$. To this end, we consider the total strain at $70 \%$ of the UCS as our damage threshold.

The next step is determining the damage evolution under uniaxial loading beyond this threshold. In order to experimentally obtain the damage evolution, one would need to perform a series of loading-unloading cycles after the threshold, but this approach is problematic, especially after the peak of the loading 
curve, and has not been used in this work. This is simply because the specimen typically loses its structural integrity during unloading (after the peak) and thus further loading cannot be continued, although other authors, notably Djerbi Tegguer et al [10] have succeeded in circumventing this issue. The literature indicates very little research on possible damage thresholds and, more importantly, damage evolutions with load/strain for mortar under uniaxial compression, with the exception of Mazars' seminal work [46, 47, 48], however this is a purely elastic-damage model that does not allow for plastic strains. In order to obtain the damage evolution under compressive loading for our mortar beyond our chosen threshold, we decided to fit the experimentally obtained mortar behaviour under uniaxial compression, i.e. the envelope curve generated by the CEB-FIP model with our experimental data, to the envelope curve presented by [39] with this damage threshold using three control points (figure $5)$ :

1. the elastic limit $f_{0}$,

2. the peak point of the experimental (CEB-FIP) curve $\left(\varepsilon_{c}, f_{c}\right)$ and

3. a third operating point $\left(\varepsilon_{o p}, f_{o p}\right)$ to represent the post-peak softening behavior

using the following relations:

$$
\begin{gathered}
A_{c}=\frac{f_{c}-\varepsilon_{e l} Y_{m}}{Y_{m}\left(\varepsilon_{c} \exp \left(\varepsilon_{e l} / \varepsilon_{c}-1\right)-\varepsilon_{e l}\right)} \\
B_{c}=\frac{f_{o p} \varepsilon_{c} \exp \left(\varepsilon_{e l} / \varepsilon_{c}-1\right)-\varepsilon_{o p} f_{c} \exp \left(\varepsilon_{e l} / \varepsilon_{c}\left(1-\varepsilon_{u} / \varepsilon_{e l}\right)\right)}{E_{m} o r *\left(\varepsilon_{c} \exp \left(\varepsilon_{e l} / \varepsilon_{c}-1\right)-\varepsilon_{o p} \exp \left(\varepsilon_{e l} / \varepsilon_{c}\left(1-\varepsilon_{u} / \varepsilon_{e l}\right)\right)\right)} \\
C_{c}=\frac{f_{c}-f_{o p}}{Y_{m}\left(\varepsilon_{c} \exp \left(\varepsilon_{e l} / \varepsilon_{c}-1\right)-\varepsilon_{o p} \exp \left(\varepsilon_{e l} / \varepsilon_{c}\left(1-\varepsilon_{u} / \varepsilon_{e l}\right)\right)\right)}
\end{gathered}
$$

This yields the damage evolution with inelastic strain in the following equation (the isotropic damage variable $d=0$ below the damage threshold $0.7 f_{c}$ ):

$$
\begin{array}{r}
d\left(0.7 f_{c} \leq \sigma \leq f_{c}\right)=1-\left(1-A_{c}\right) \frac{\varepsilon_{e l}}{\varepsilon}-A_{c} \exp \left(\frac{\varepsilon_{e l}-\varepsilon}{\varepsilon_{c}}\right) \\
d\left(\sigma>f_{c}\right)=1-\frac{B_{c}}{\varepsilon}-C_{c} \exp \left(\frac{\varepsilon_{e l}-\varepsilon}{\varepsilon_{c}}\right)
\end{array}
$$




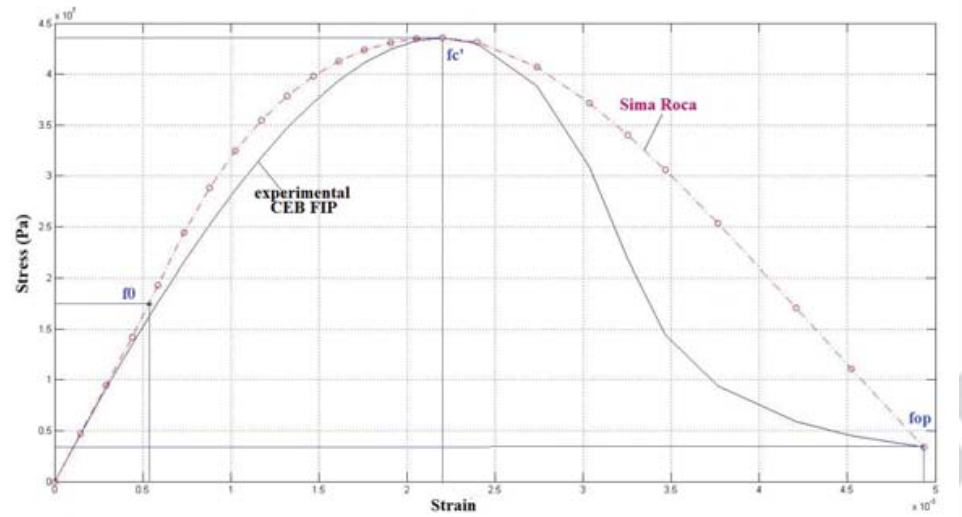

Figure 5: Three-point fitting the Sima-Roca enveloppe curve to an experimental compression test

The obtained $\varepsilon-d$ evolution (for the chosen threshold) is shown in figure 6 .

The "fitted" stress-strain relation that we will use for the 3D mesocale model
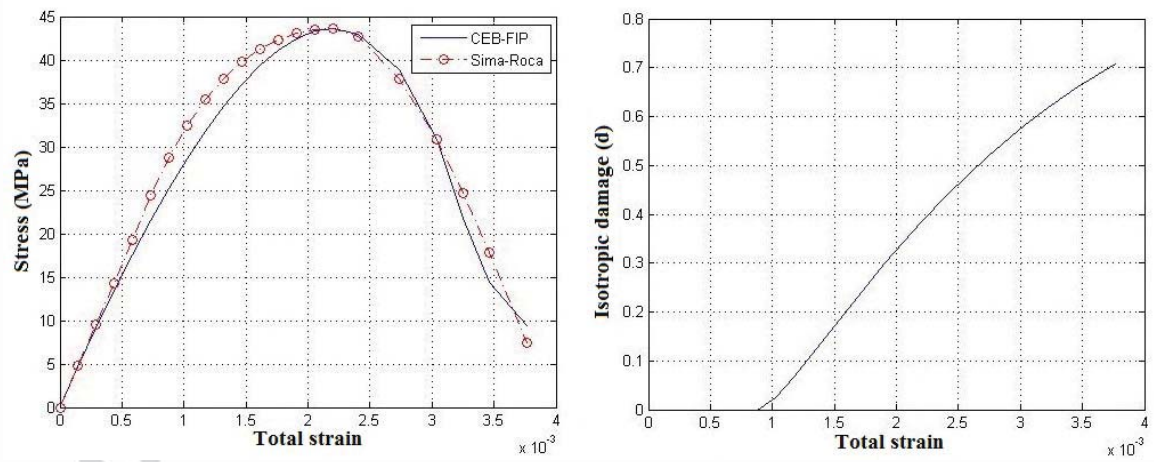

Figure 6: Damage evolution with the strain at $70 \%$ as damage threshold 
is then given by:

$$
\begin{array}{r}
\sigma\left(\varepsilon \leq \varepsilon_{e l}\right)=Y_{m} \varepsilon \\
\sigma\left(\varepsilon_{e l} \leq \varepsilon \leq \varepsilon_{c}\right)=Y_{m}\left[\varepsilon_{e l}\left(1-A_{c}\right)+A_{c} \varepsilon \exp \left(\frac{\varepsilon_{e l}-\varepsilon}{\varepsilon_{c}}\right)\right] \\
\sigma\left(\varepsilon \geq \varepsilon_{c}\right)=Y_{m}\left[B_{c}+C_{c} \exp \left(\frac{\varepsilon_{e l}-\varepsilon}{\varepsilon_{c}}\right)\right]
\end{array}
$$

for compression, and:

$$
\begin{array}{r}
\sigma\left(\varepsilon \leq \varepsilon_{e l}\right)=Y_{m} \varepsilon \\
\sigma\left(\varepsilon \geq \varepsilon_{c}\right)=Y_{m}\left[\varepsilon_{t} \exp \left(\alpha \frac{\varepsilon_{e l}-\varepsilon_{t}}{\varepsilon_{t}}\right)\right]
\end{array}
$$

under tension.

The alternative to using the approach in this subsection would be to use the actual experimental load-displacement curve with progressive unloading for a series of increments after the damage threshold. This is almost never realistic with a cementitious composite, and the semi-analytical-experimental method used here has been validated in the literature reviewed [39].

\subsubsection{Transport properties (hygral behavior)}

Moisture transport within the composite specimen may be elegantly described by combining the law of conservation of mass and Darcy's equation as follows:

$$
\operatorname{div}(\mathbf{q})=\dot{S}=\frac{\partial S}{\partial P_{c}} \frac{\partial P_{c}}{\partial t}=\operatorname{div}\left(\mathbf{K} \frac{k_{r e l}(S)}{\mu_{l} \phi} \cdot \nabla P_{c}\right)
$$

where $\mathbf{q}$ is the moisture flux, $\mathbf{K}$ is the intrinsic isothermal permeability tensor of the mortar, $k_{r e l}$ is the relative permeability, $S$ is the degree of saturation, $P_{c}$ is the capillary suction pressure, $\phi$ is the porosity and $\mu_{l}$ is the viscosity of water.

Van Genuchten's closed-form expression [49] may be used to obtain the relative permeability as follows:

$$
k_{r e l}(S)=\sqrt{S}\left[1-\left(1-S^{b}\right)^{\frac{1}{b}}\right]
$$


This means that the distribution of relative humidity in the porous phases will have a drastic effect on the permeability levels. For this work we will assume that the individual phases are homogenous and isotropic with a uniform relative humidity $h_{r}$ of $50 \%$, i.e. partially saturated. This means that any moisture transport would have to be considered to be at steady state.

Returning to (13), we can write the equation for flow through the macroscopic material (composite specimen) in the following fashion:

$$
\mathbf{Q}=-\frac{\rho}{\mu} \mathbf{K} \cdot \mathbf{G}
$$

where $\mathbf{Q}=$ macroscopic moisture flux, and $\mathbf{G}=$ macroscpic pressure gradient

$$
\mathbf{Q}=\frac{1}{V} \int_{V} \mathbf{q}(\mathbf{x}) d V, \mathbf{G}=\frac{1}{V} \int_{V} \nabla P(\mathbf{x}) d V
$$

obtained by averaging over the heterogenous material domain.

This basically means the moisture transport alters the distribution of both $S$ and $h_{r}$ within the specimen until steady-state is established.

The traditional practice is applying uniform pressure boundary conditions on the boundary allowing us to calculate the 9 components of the macroscopic permeability tensor $\mathbf{K}$ by solving (15) using the method of finite elements. However, this method is not very practical for specimens with multiple heterogenities and that do not have very straightforward geometries, not to mention timeconsuming. In the last subsection, we will outline a numerical approach that does not require FE evaluations.

\subsubsection{Mechano-hygral coupling under load}

In the composite under load, there exists a strong mechano-hygral as well as hygro-mechanical coupling. For the first, the distribution of $S$ generates a capillary pressure $P_{c}(S)$ throughout the porous phase(s) that in turns creates a hydrostatic pressure distribution inside the composite. Returning to Van Genuchten's closed-form expression for the capillary pressure $P_{c}[49]$ we have:

$$
P_{c}(S)=a\left(S^{-b}-1\right)^{\left(1-\frac{1}{b}\right)}
$$


The Laplace and Kelvin equations may then be combined to show the relation between the relative humidity $h_{r}$ and the capillary suction pressure $P_{c}$, as given in the following equation [50].

$$
P_{c}\left(h_{r}\right)=\frac{\rho R T \log \left(h_{r}\right)}{M_{w}}
$$

This pressure must ordinarily be taken into account during the FE simulation of the mechanical response of the composite specimen. However, we make two assumptions: only the mortar phase is porous and sufficiently saturated, so that we can neglect the effect of capillary pressure during the simulation of mechanical behavior. Taking this into account, however, is fairly straightforward using a homogenization coefficient.

This means that the FE simulation for the composite under load is carried out according to the first two subsections in this section, without considering the effect of capillary suction pressure on the mortar phase. Once the required FE simulation has been completed, we now have the simulated damage $(d)$ values for every single finite element in each phase, at various loading points of interest throughout the test.

Since only the mortar phase is damageable in this paper, we then link the calculated damage value for an element of mortar with the subsequent increase in permeability. We return to the primary contributions in this area as given in the introductory section. Following [11], we consider a logarithmic matching law between the empirical relationship of Picandet et al [6] for damage in the pre-peak region of the compression curve of the mortar phase:

$$
K_{l}^{\text {mor }}(d)=K_{0}\left(1+\alpha d^{\beta}+\frac{1}{2} \alpha d^{2 \beta}+\frac{1}{6} \alpha d^{3 \beta}\right)
$$

and Poiseuille's law for flow through a crack of roughness $\zeta$ and opening $[U]$ gives the crack permeability as:

$$
K_{c k}=\frac{\zeta[U]^{2}}{12}
$$

The idea then is to represent the "diffuse" damage variable $d$ by an effective crack. This means mapping the damage band (diffuse description) to a strong 
discontinuity $[11,13]$, allowing us to represent the permeability of damaged mortar by:

$$
K_{p}^{m o r}(\varepsilon)=\frac{\zeta}{12}[U]^{2} \cdot \frac{[U]}{\lambda l_{c}}=\frac{\zeta}{12 \lambda l_{c}}[U(\varepsilon)]^{3}
$$

where $\lambda l_{c}$ is the width of the damage band corresponding to the strong discontinuity $[U]$ of the effective crack opening or amplitude of the discontinuity appearing within the material when it is completely degraded locally (damage $d \approx 1$ ). This can be related to the strain $\varepsilon$ and damage threshold $\varepsilon_{T}$ (strain at $70 \%$ of the peak):

$$
[U(\varepsilon)]=\left(\varepsilon-\varepsilon_{T}\right) \lambda l_{c}
$$

The Picandet relationship tends to hold well for relatively low values of isotropic

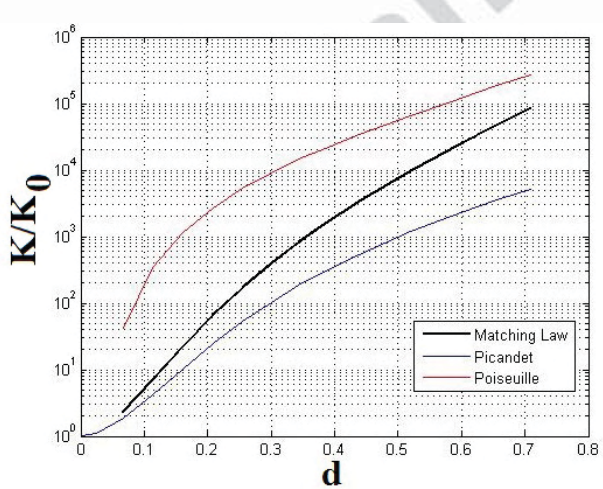

Figure 7: Logarithmic matching law between Picandet's empirical relation (pre-peak) and Poiseuille's effective crack-based relation (post-peak) for the mortar phase

damage $d$ while Poiseuille's relationship with the effective crack assumption gives a good estimate of damaged mortar permeability for values of $d$ close to 1 . Similarly to [11] then, we consider a logarithmic weighted relationship between the two estimates giving:

$$
\log \left(K^{\text {mor }}(\varepsilon, d)\right)=(1-d) \log \left(K_{l}^{\text {mor }}(d)\right)+d \log \left(K_{p}^{\text {mor }}(\varepsilon)\right)
$$


The obtained weighted relationship, shown in figure 7 , allows us to move to the last phase of the mesoscale model: estimating the macroscopic permeability tensor for the heterogenous composite.

\subsubsection{Numerical estimation of the macroscopic permeability tensor}

In order to calculate the damaged macroscopic permeability tensor $\mathbf{K}_{\mathbf{D}}$, we have followed our previous aproach in [26], and represented the specimen by a series of inter-connected cylinders of identical diameter, using however, a conforming mesh - in fact the very same FE mesh used for the mechanical analysis - rather than a non-conforming mesh that ignores the heterogenities which was used in our previous work. Admittedly, this will introduce some degree of mesh-dependence in the results obtained when comparing the results obtained during different mechanical analyses, but will significantly save on computational time and effort since the element-wise $\epsilon-d$ results may directly be used to estimate damaged permeability values without a costly interpolation or Diffuse Approximation [51].

Based on the previous work, the directional damaged permeability tensor $\mathbf{k}_{\mathbf{D}}{ }^{v}$ of the $v^{t h}$ cylinder with length $L_{f}$ (which varies throughout the mortar phase depending on the FE element sizes) and inclined at angles $\theta$ and $\phi$ (figure 8) is

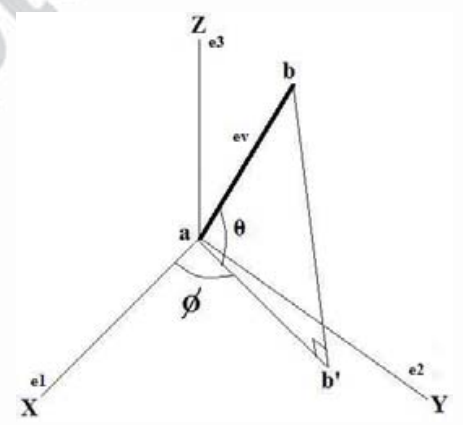

Figure 8: Orientation angles $\theta$ and $\phi$ for the $v^{t h}$ 'cylinder' 
then given by the Poiseuille formula for 1D flow:

$$
\begin{array}{r}
\mathbf{k}_{\mathbf{D}}{ }^{v}=k^{\text {mor }}(\varepsilon, d) \bar{e}_{v} \otimes \bar{e}_{v}=k_{i j}^{v}(\varepsilon, d, \theta, \phi) \bar{e}_{i} \otimes \bar{e}_{j} \text { where } k_{i j}^{v}(\theta, \phi)= \\
k^{m o r}(\varepsilon, d)\left[\begin{array}{ccc}
\cos ^{2}(\theta) \cos ^{2}(\phi) & \cos ^{2}(\theta) \cos (\phi) & -\frac{1}{2} \sin (2 \theta) \cos (\phi) \\
\cos ^{2}(\theta) \cos (\phi) & \cos ^{2}(\theta) \sin ^{2}(\phi) & -\frac{1}{2} \sin (\theta) \sin (2 \phi) \\
-\frac{1}{2} \sin (2 \theta) \cos (\phi) & -\frac{1}{2} \sin (\theta) \sin (2 \phi) & \sin ^{2}(\theta)
\end{array}\right]
\end{array}
$$

Percolation of each cylinder is then taken into account by monitoring the location of its endpoints using the level set functions $[52,53]$ of the aggregate shapes in order to associate the cylinder in question with either the intrinsic permeability of the mortar or that of the aggregates. For cylinders that are completely located within a single phase, its permeability is assumed to be the mean damaged permeability of the two connected finite elements.

Finally, we obtain the macroscopic tensor by assembling all the individual contributions.

\subsection{Phase II: Aggregates}

The inclusions or aggregates in concrete may be silicious, calcareous, plastic or vegetal in origin, with corresponding matrix-inclusion contact criteria. For example, calcareous aggregates generally are in perfect contact with the mortar and plastic aggregates have a frictionless sliding contact with the mortar.

The traditional approach is to assume linear-elastic-brittle behavior for the aggregates in the mechanical model. Aggregates may also be assumed to have negligibly low permeability as our previous research has showed, even though taking these into account with our approach is extremely simple [26].

\subsection{Phase III: Interfacial Transition Zone}

In the general case, we need to consider the effect of a third phase, called ITZ, as an extension of the first phase embedding the aggregates. In this particular study, just as in [26], the ITZ has been assumed to have no influence on the overall compressive behavior of the concrete specimen $[25,54]$ or on the homogenized transport properties [54]. This is validated by [55] where we note 
that even though the ITZ plays a role in the crack propagation paths, there is no real effect on the increase in the overall macroscopic damaged permeability. The explanation for this is found in some detail in [54], the presence of a zone with higher porosity (i.e. ITZ) around the aggregates modifies the structure of the paste farther away from the aggregates and leads to a decrease in the porosity of the bulk paste so as to respect the moisture conservation.

In other words, the structure of the bulk paste of the mortar phase is different from that of the paste with the same $\mathrm{w} / \mathrm{c}$ ratio but without a granular skeleton. There is thus only a slight effect of ITZ on the overall uniaxial compressive behavior of mortar as well as on its diffusivity (transport behavior), since the decrease of the porosity in the bulk paste, in effect, counterbalances the increased porosity in the ITZ. In other words, the ITZ phase only alters the crack patterns (damage is concentrated in this zone instead of away from it), so the net change in calculated permeability is negligible. This is clear when we consider the nature of the network mode. the calculated macroscopic permeability involves a "summation" / assembly of the contribution of individual crack patterns (damaged elements) and the net contribution of two different patterns could well be identical, as in the total amount of "damage", leading thus to negligible differences in the calculated permeability.

\section{Results and Discussion}

\subsection{Mechanical Behavior of the composite}

Virtual cylindrical composite specimens $\phi 110 \times h 50 \mathrm{~mm}$ were generated at various aggregate volume fractions $10 \%, 20 \%, 24 \%, 28 \%$ and $30 \%$ for the experimental granulometric distribution, and for a uniform granulometric distribution (D50 or the median effective diameter of the experimental distribution) at $28 \%$ volume fraction using the algorithms mentioned in section 3 . These were then meshed using the GMSH algorithm [56] to obtain corresponding FE meshes, as seen in section 2. The material behavior followed the envelope curve fitted to the experimental compression test and the damage evolution followed 
section 4.1.2. Using a Drucker Prager yield criterion in ABAQUS, FE simulations were performed for two different boundary conditions at the bottom face for the various virtual composite specimens.

The displacement-based compression test was controlled at a speed of $0.25 \mu \mathrm{m} / \mathrm{s}$ and was carried out until failure of the specimen or excessive element distortion. Three different mesostructures with different random aggregate arrangements were studied at $28 \%$ volume fraction and the variation of the simulated UCS was found to be $\leq 1 \mathrm{MPa}$ thus allowing us to use a single mesostructure per aggregate volume fraction for the various FE mechanical simulations.

The first main step then was to identify the appropriate boundary conditions on the bottom face so as to accurately represent the experimental conditions during the FE simulation. Figure 9 and 11 show that this has an extremely significant effect on the simulation results obtained for the mechanical behavior of the specimen.

Comparing the simulated UCS of the specimen at $28 \%$ with the experimen-

\begin{tabular}{|c|c|c|}
\hline Boundary condition & UCS $(\mathrm{MPa})$ & $Y_{c}(\mathrm{GPa})$ \\
\hline \hline Built-in & 53.3986 & 42.386 \\
\hline Simply supported & 33.2310 & 40.740 \\
\hline \hline
\end{tabular}

Table 5: Comparison of simulated UCS for specimen at $28 \%$ fraction using the two boundary conditions

tally obtained value of $52.8 \mathrm{MPa}$ (table 5 ), we see that the built-in conditions better represent the loading conditions. This is clearly because the specimen was compressed on a non-lubricated steel plate, thus the coefficient of friction was sufficient to prevent non-vertical displacement at the bottom face. In addition, during the experimental compression of the specimen at $28 \%$, we observed that the damage was localized towards the exterior of the specimen (figure 10): similar to what was obtained with the built-in boundary conditions (figure 11), rather than spread out over the entire section. Hence, we retain the built-in boundary conditions for the bottom face for the remaining sets of results. 


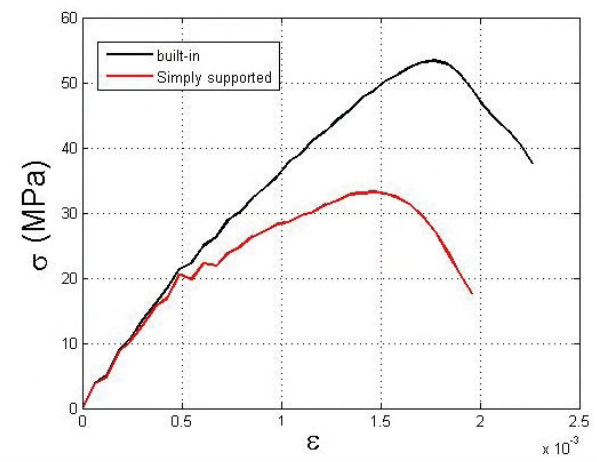

Figure 9: Effect of boundary conditions on bottom face of virtual specimen on the compression curve during a uniaxial compression test on $\phi 110 \times h 50$ cylindrical concrete specimen at 28 $\%$ aggregate volume fraction

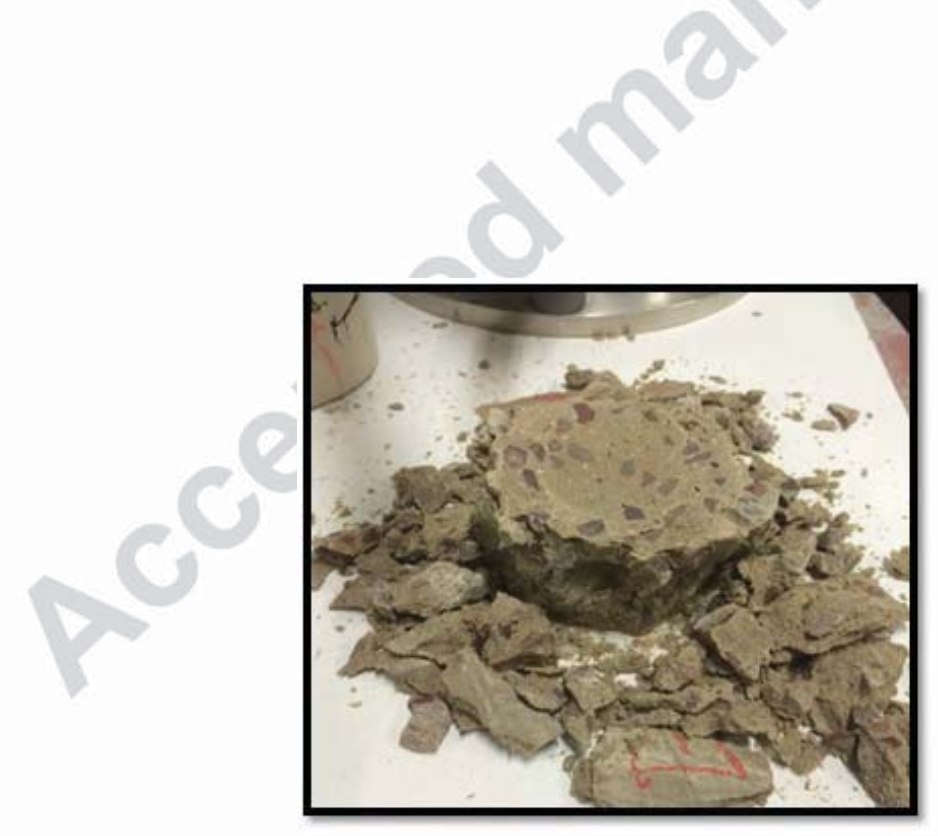

Figure 10: Damage distribution inside experimental specimen after removal 


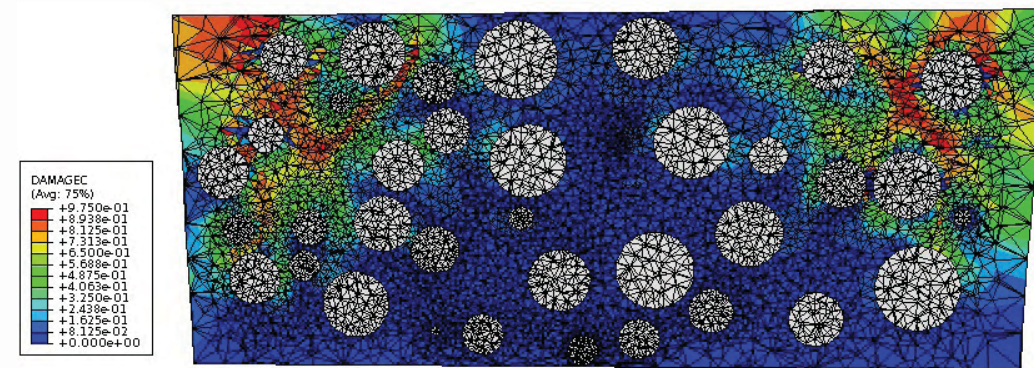

Built-in boundary conditions at bottom face

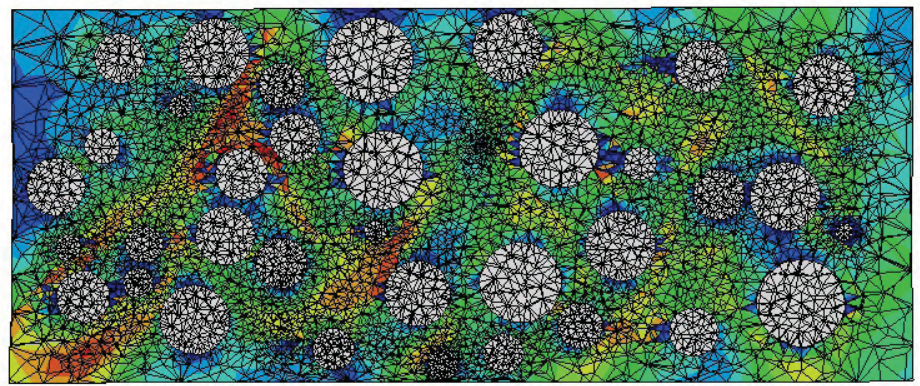

Simply supported (smooth contact) at bottom surface

Figure 11: Comparison of two different boundary conditions on bottom face of virtual specimen during uniaxial compression at $28 \%$ aggregate volume fraction on damage distribution inside specimen (sectional view) 
Next, we performed the FE simulations for the 4 different aggregate fractions (figure 12), and as we expect, the UCS appears to increase with increasing fraction from 10 to $20 \%$, but from $20 \%$ to $30 \%$ (classical aggregate fractions for industrial concretes) the evolution is not monotonic and we observe a reduction in UCS for aggregate fractions in the neighborhood of $24 \%$ (figure 13), a phenomenon that we have seen previously [26] and has also been observed experimentally [29].

As expected from experimental observations made in the literature (e.g. [57]), and can be easily verified by calculating the Mori-Tanaka homogenized modulus for the composite [26], the Young's modulus increases in almost linear fashion with the aggregate fraction since the aggregates have a higher rigidity compared to mortar.

The typical evolution of damage distribution on the external surfaces of the

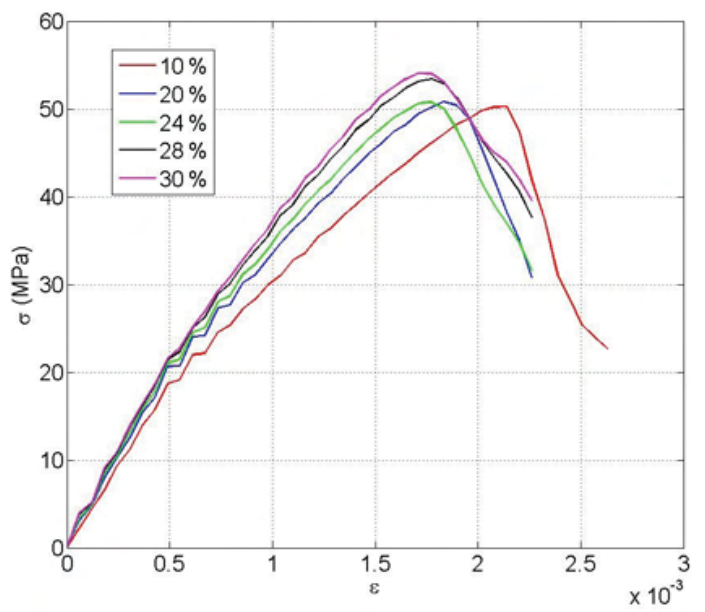

Figure 12: Effect of aggregate volume fraction on the compressive behavior during a uniaxial compression test on $\phi 110 \times h 50 \mathrm{~mm}$ concrete specimen

cylindrical specimen at $28 \%$ is shown in figure 14 . Finally, figure 15 shows that changing the aggregate granulometric distribution at the same volume fraction has a significant influence on the mechanical response. The figure compares the simulation results obtained for two virtual specimens at $28 \%$, the first with the 

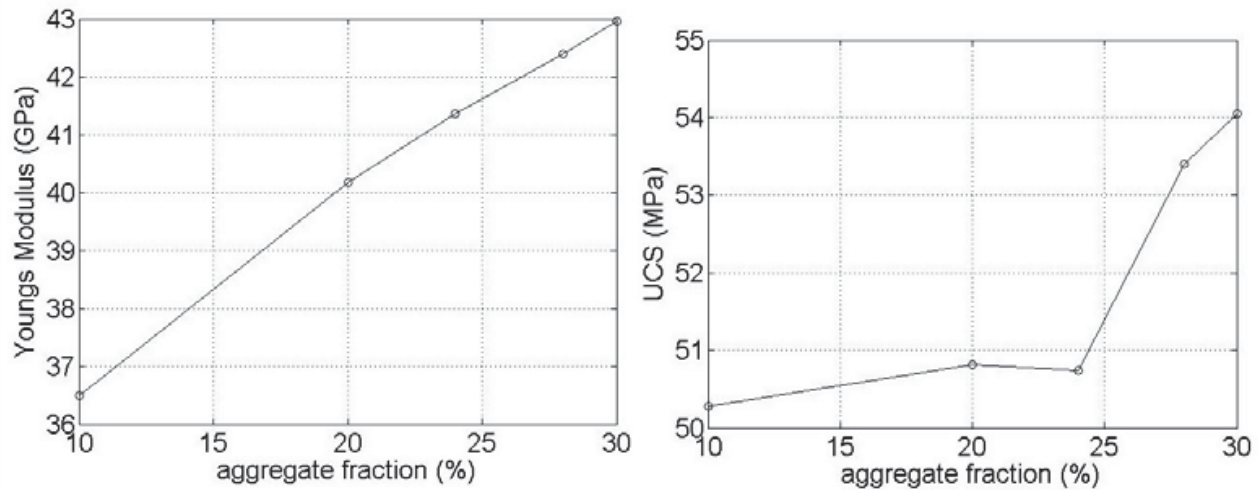

Figure 13: Effect of aggregate volume fraction on the UCS and Young's modulus of a $\phi 110 \times h 50$ mm specimen undergoing uniaxial compression

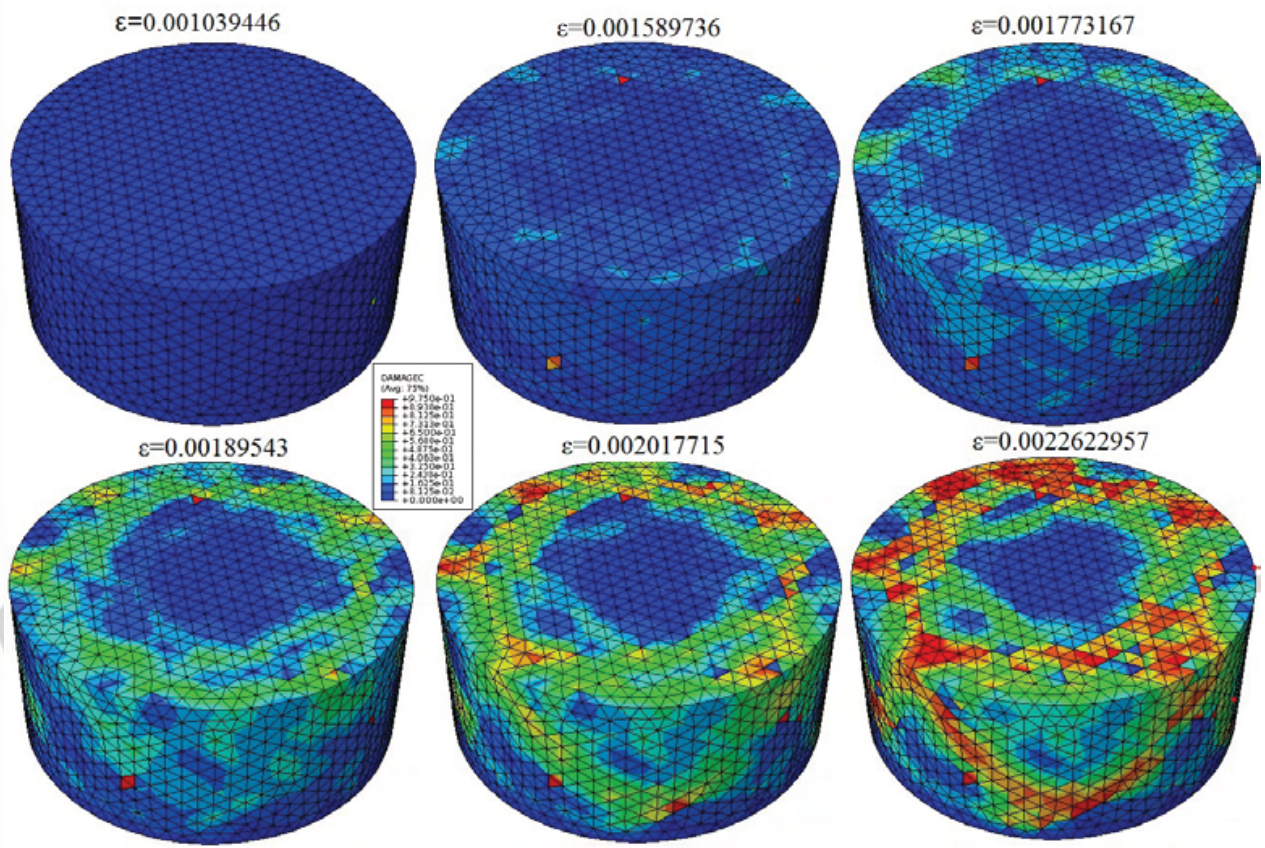

Figure 14: Damage distribution on the external surfaces at various points on the simulated uniaxial compression curve for the specimen at $28 \%$ aggregate fraction 
experimental granulometric distribution and the second with a uniform distribution, i.e. every aggregate having the same diameter $=$ the median aggregate diameter of the experimental distribution.

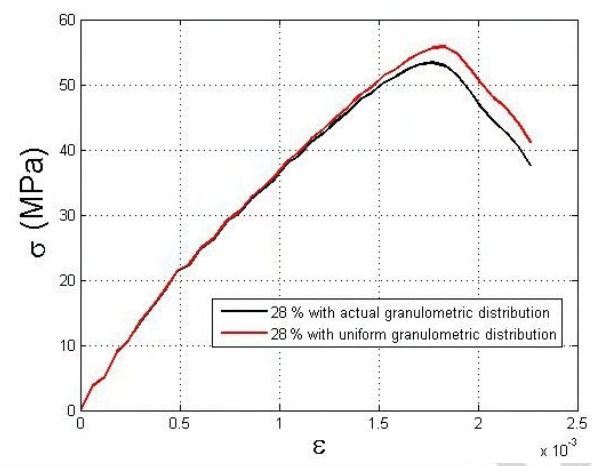

Figure 15: Effect of granulometric distribution on the compressive behavior during a uniaxial compression test on $\phi 110 \times h 50 \mathrm{~mm}$ cylindrical concrete specimen at $28 \%$ aggregate volume fraction

\subsection{Identification of the matching law parameters using the experimental results}

Before we can use the relations in section 4.1.3 to associate the damage values at different points in the mortar phase of the composite with damaged permeability values, we need to identify the two Picandet $(\alpha, \beta)$ and/or two Poiseuille parameters (damage band width $\lambda l_{c}$ and crack roughness $\zeta$ ) respectively. Depending on the damage values and the number of experimental points available, we can identify anywhere between 1 and 4 parameters. For the identification problem to be well-posed, we ideally need 4 experimental points, 2 in the pre-peak region and 2 in the post-peak region. However, regardless of the number of points, the identification procedure would remain the same, and only the uniqueness of the solution obtained would be in question.

In the current work, we have obtained a single experimental point with the increase in damaged permeability $K_{D} / K_{u}$ measured at 3.75 for the experimental $\phi 110 \times 20 \mathrm{~mm}$ specimen at $28 \%$ aggregate fraction, and loaded at $88 \%$ of the 
UCS, with the damage value measured at 0.1 by the acoustic emission technique. For low damage values in the pre-peak region of the loading curve, the Picandet relationship typically yields a good estimate of the damaged permeability [11] allowing us to obtain the locus of all solutions for $\mathbf{p} \equiv(\alpha, \beta)$ by solving the inverse problem:

$$
\begin{array}{r}
\mathbf{p}=\operatorname{Argmin}_{\mathbf{p} \in \mathcal{S}} J(\mathbf{p})=\operatorname{Argmin}_{\mathbf{p} \in \mathcal{S}}\left|\frac{\operatorname{tr}\left(\mathbf{K}_{\mathbf{D}}(\mathbf{p}, \varepsilon)\right)}{\operatorname{tr}\left(\mathbf{K}_{\mathbf{D}}(\mathbf{p}, 0)\right)}-3.75\right| \\
\text { where } \mathcal{S}=\left\{\mathbf{p} \in \mathcal{R}_{+}^{2}\right\}
\end{array}
$$

where Argmin referes to the value of the argument for which the function returns a minimum value.

The curve in the inset of figure 16 is the locus obtained, with 5 example solu-

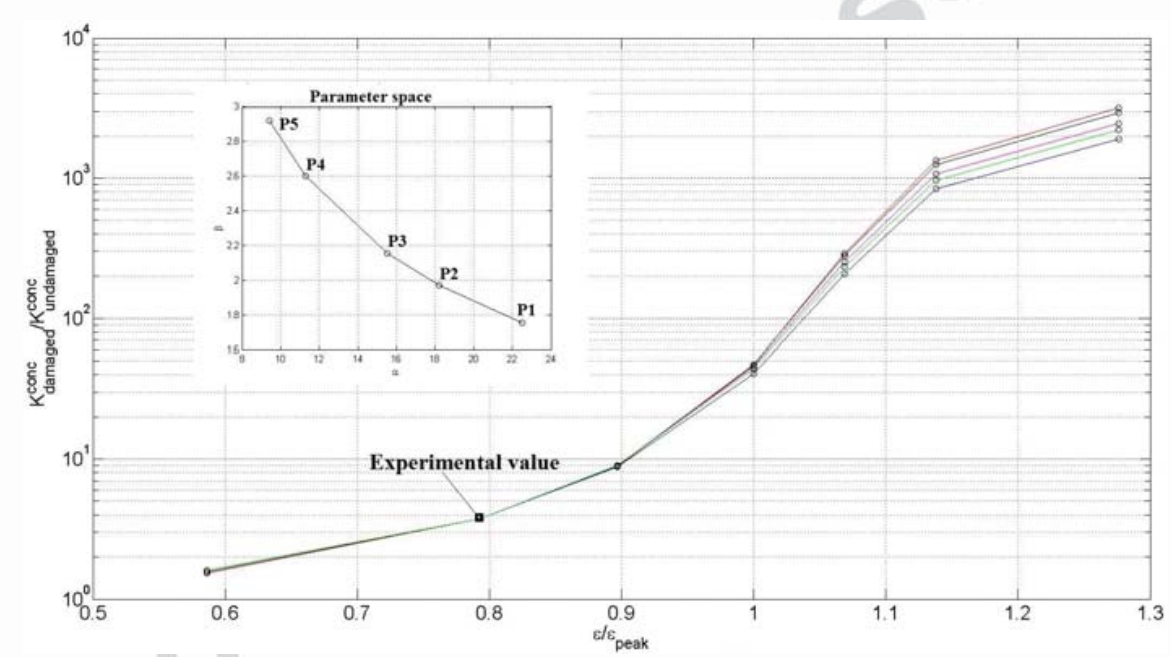

Figure 16: Identification of the Picandet parameters using the experimentally obtained damaged permeability at $88 \%$ of the UCS for cylndrical concrete specimen at $28 \%$ aggregate fraction

tions shown.

$$
\beta(\alpha)=2 \times 10^{-5} \alpha^{4}+1.9 \times 10^{-3} \alpha^{3}+5.68 \times 10^{-2} \alpha^{2}-0.8459 \alpha+7.2263
$$

We obtained this solution by solving the inverse problem in (25) using the Nelder-Mead Simplex method [58] programmed in MATLAB. This algorithm 
is popular for inverse problems with a significant computational effort per objective function evaluation since it does not require gradients/Hessian calculations. It is a heuristic derivative-free response surface optimization method that uses the concept of a simplex, a special polytope of $(N+1)$ vertices in $N$ dimensions $\left(\mathbf{p}^{1} . \mathbf{p}^{N+1}\right)$ ordered according to the value of the objective function/identification error $J$.

$$
J\left(\bar{V}_{1}\right) \leq J\left(\bar{V}_{2}\right) \leq \ldots \leq J\left(\bar{V}_{N+1}\right)
$$

It then extrapolates the value of $J^{i}$ measured at each test point $\bar{V}^{i}$, in order to find a new test point $\bar{V}_{N+2}$ and to replace ONE of the old $N+1$ test points with the new one, and repeat till convergence. We typically replace the worst point with a point reflected through the centroid $\bar{V}_{0}=\left(\sum_{1}^{N} \bar{V}_{i}\right) / N$ of the remaining $N$ points. The identification algorithm does NOT change with the number of experimental points, although the problem needs at least 2 for a unique solution. Similarly, 2 additional points in the post-peak damaged state would allow us to identify all parameters in the matching law of section 4.1.3.

For each of these 5 identified solutions, we plot the simulated evolution of damaged permeability for the composite specimen in the main figure 16, for which we assume fairly standard values for the post-peak progression, i.e. Poiseuille parameters $\lambda l_{c}=0.04$ and crack roughness $\zeta=1$ (from [11])

\subsection{Evolution of permeability with progressive damage}

Now that we have 5 sets of Picandet parameters to represent the hygromechanical coupling for our concrete (at low damage levels) we then use the same set of Poiseuille parameters as in the previous section to complete the matching law and one of the sample identified solutions for the Picandet parameters $\alpha=18.19, \beta=1.97$ for our particular mortar, and simulate the permeability evolution throughout the load-damage progression, by calculating the macroscopic tensor using the calculated damage values from the first subsection. This was done for each of the 5 different virtual composite specimens, as well as assuming the two different boundary conditions and two different granulometric 
distributions for the specimen at $28 \%$ aggregate fraction. Finally we considered the two possible damage thresholds for the mortar phase. The results of the

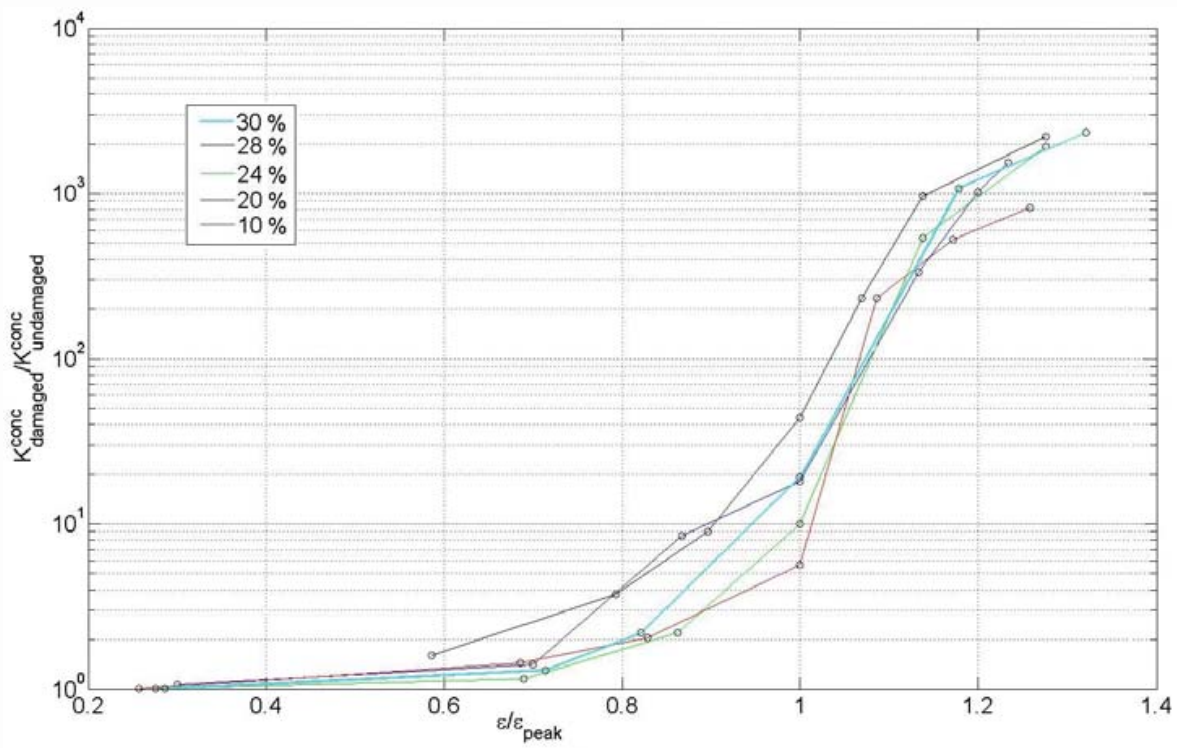

Figure 17: Evolution of damaged permeability at different aggregate volume fractions

mesoscale simulation are shown in figures 17, 18 and 19 respectively. It is clear that the damage distribution in the mortar phase is responsible for the surge in permeability, beginning near around 50-60 \% of the peak of the compression curve and then rapidly increasing as the mortar phase progressively undergoes complete deterioration. We note that the increase in permeability, while still in the order of a few thousand, still pales somewhat in comparison to the increase in permeability for a pure mortar specimen (section 4.1.3). This is because the presence of aggregates in the composite limits the propagation of damage throughout the specimen.

Increasing aggregate fraction does not have a clearly monotonic effect on the damaged permeability at every single point, this is because the local damage distributions in the mortar phase are highly nonlinear. We may state that the $28 \%$ specimen sustains more damage than the $10 \%$ specimen allowing for an 


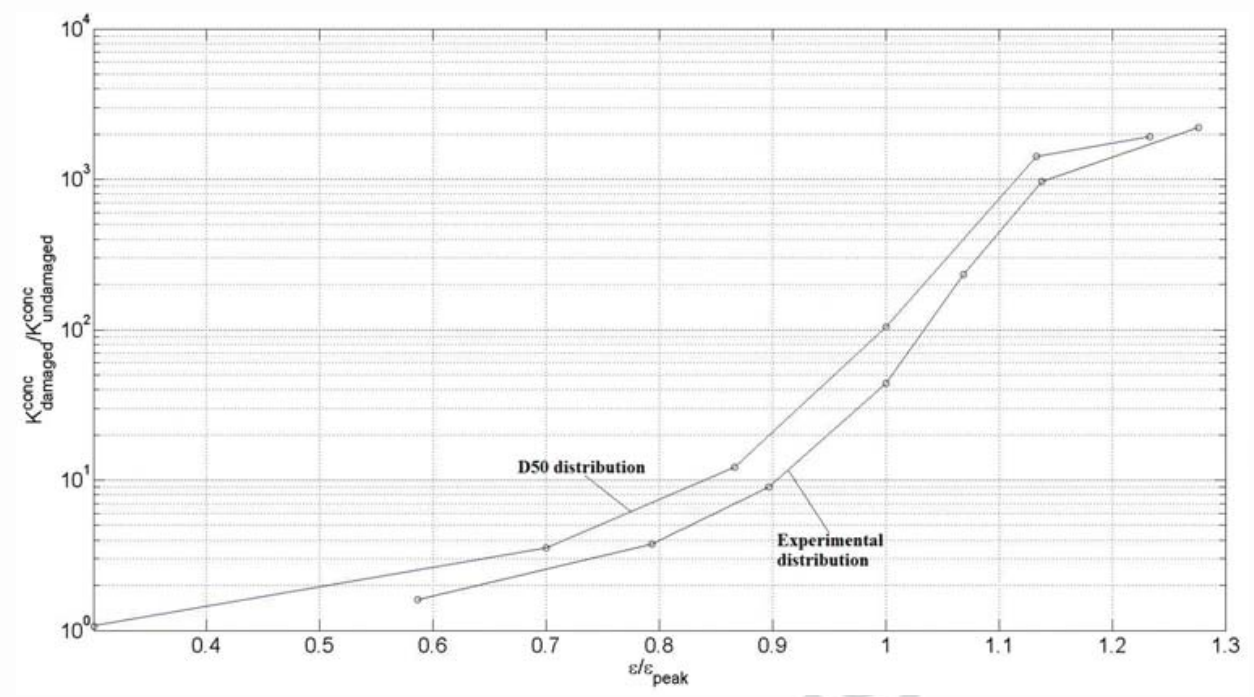

Figure 18: Evolution of damaged permeability for different granulometric distributions at 28 $\%$ aggregate volume fraction

overall increase in permeability values. But the simulation shows that direct qualitative observations are difficult to draw merely from these curves (figure 17).

The uniform granulometric distribution sustains more localized damage compared to the experimental distribution and this may explain the slight increase in damaged permeability. As far as the boundary conditions are concerned, this result should hardly be surprising, given that the simply supported boundary conditions cause a more gradual increase in damage levels compared to the built-in conditions on the bottom face. This is because the built-in conditions yield damage localized close to the exterior of the specimen while the simply supported conditions lead to a more "diffuse" distribution of damage in the interior. Next, we see the effect of two different damage thresholds (figure 20) for the mortar phase for the concrete specimen at $28 \%$ aggregate fraction, the first at $70 \%$ and the second at the peak load (for the mortar phase in uniaxial compression). This again, is completely expected since the delayed onset 


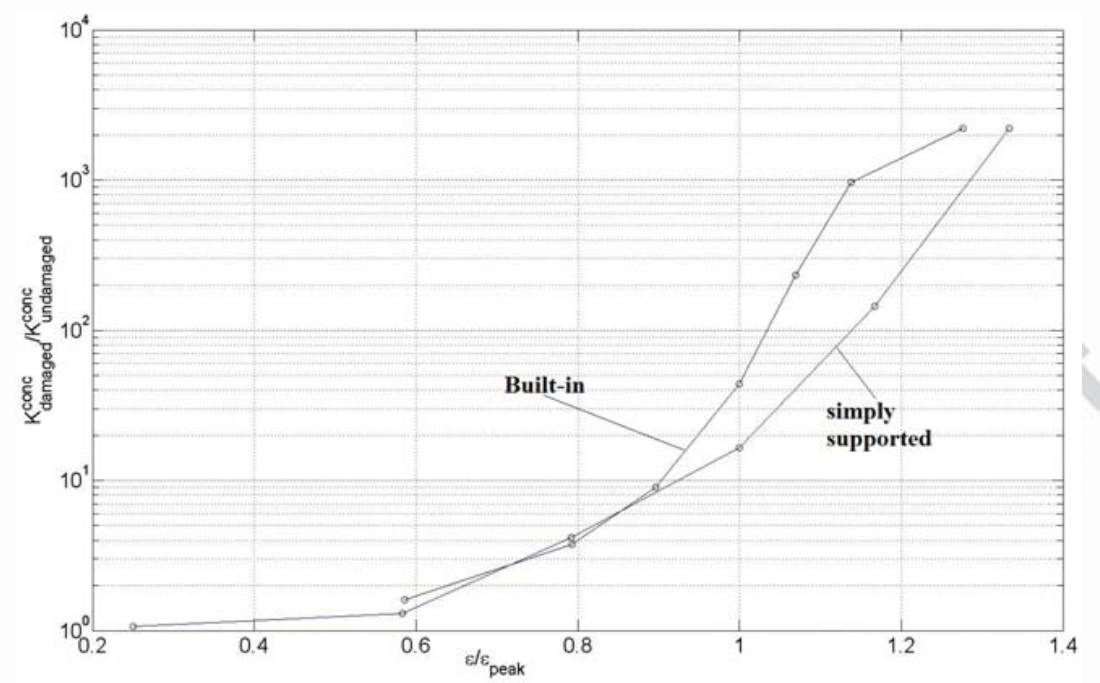

Figure 19: Effect of bottom face boundary conditions of the permeability evolution curve

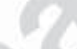

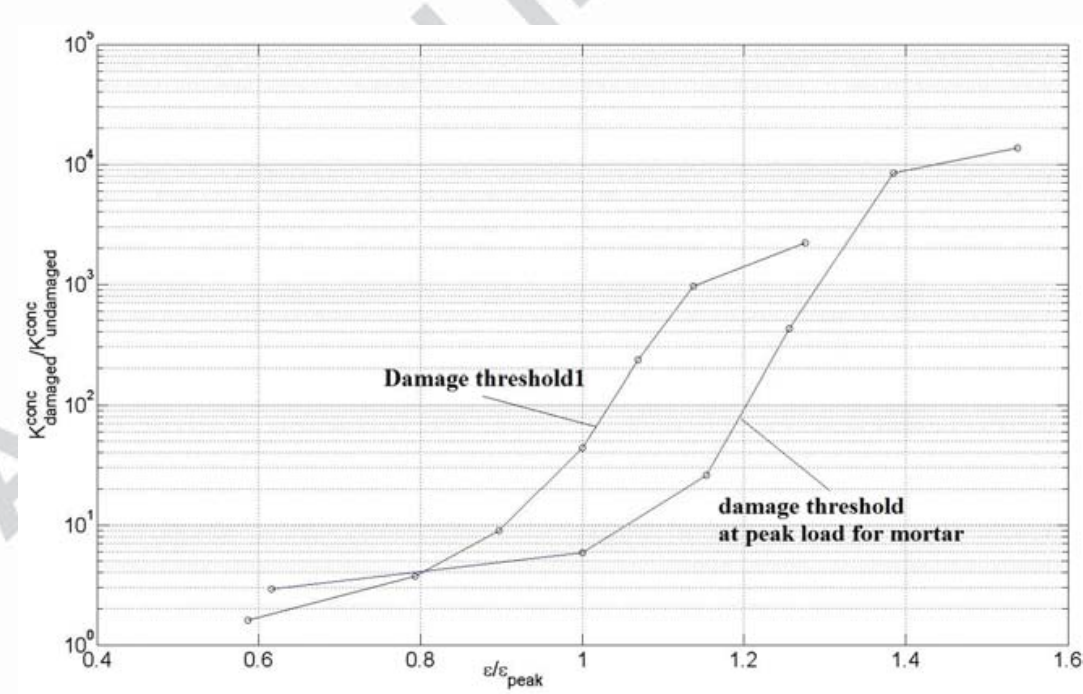

Figure 20: Effect of damage threshold on the permeability evolution curve at $28 \%$ aggregate fraction 
of damage will subsequently delay the surge in permeability. The two curves eventually meet around the same values when the material is near completely damaged. Lastly, we show the three diagonal elements of the macroscopic permeability tensor during the mechanical loading (figure 21). The undamaged tensor is isotropic (as expected), however mechanical damage marks the onset of anisotropy. However, this anisotropy appears to reduce as the specimen accumulates additional damage until complete rupture.

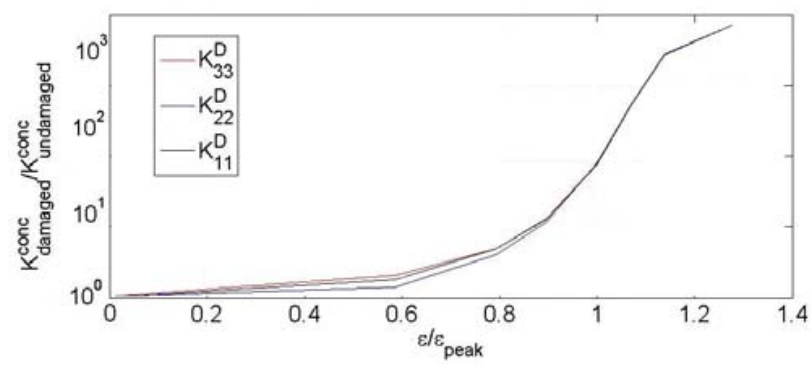

Figure 21: Anisotropy of damaged permeability tensor under progressive load

5.4. Fitting upper and lower bounds to the permeability evolution under progressive load using the Avrami equation

Since we are now clearly able to simulate the permeability increase in damaged concrete at various aggregate fractions (not to mention granulometric distributions) and at any point on the loading curve, a logical last step would then be to fit a mathematical relation for the upper and lower bounds of $\left(K_{D}(\varepsilon)\right.$. While polynomial fits are an easy approach, the very shape of the curves we have obtained leads us to consider the Avrami equation [59] that is common in problems related to crystallization kinetics, initially developed by Kolmogorov [60]. The Avrami equation has also been applied to cementitious composites by $[61]$.

To this end, we first construct the convex hull of the points in Avrami coordinate space, followed by two different fits, the first a traditional linear fit for the 
bounding envelope curves:

$$
\log \left[-\log \left(1-\frac{K_{D}}{K_{D}^{\text {max }}}\right)\right]=A_{1}+A_{2} \log \left(\frac{\varepsilon}{\varepsilon_{\text {peak }}}\right)
$$

and the second a "modified" quadratic/quadric curve fit for the same curves.

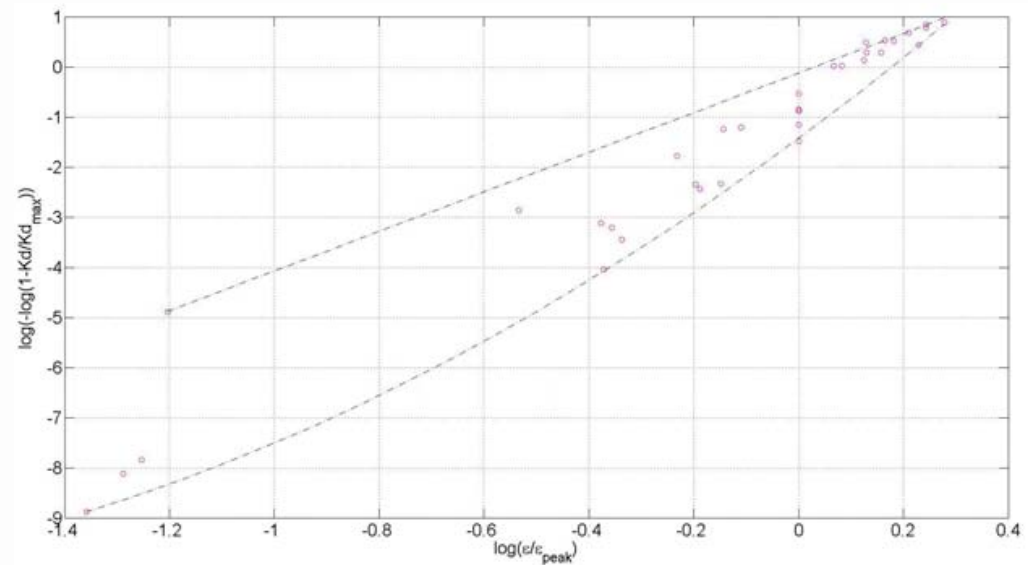

Figure 22: Fitting the traditional Avrami equation to the bounding curves generated by the convex hull

$$
\log \left[-\log \left(1-\frac{K_{D}}{K_{D}^{\text {max }}}\right)\right]=A_{1}+A_{2} \log \left(\frac{\varepsilon}{\varepsilon_{\text {peak }}}\right)+A_{3} \log \left(\frac{\varepsilon}{\varepsilon_{\text {peak }}}\right)^{2}+\ldots
$$

The results of the fitting are shown in figures 22 and 23 . While it appears that the modified Avrami equation seems to yield a better fit to the simulated solutions we have obtained, the upper bounding curve in figure 23 is not monotonic. Since we expect a purely monotonic increase in permeability with accumulated damage, we retain the first of these and, in figure 24, we plot the upper and lower bounding curves over the evolution curves plotted previously in figure 17 .

The equation of the upper bounding curve in figure 24 is:

$$
K_{D}\left(\frac{\varepsilon}{\varepsilon_{\text {peak }}}\right)=8.5347 \times\left[1-\exp \left(-0.8825\left(\frac{\varepsilon}{\varepsilon_{\text {peak }}}\right)^{3.9511}\right)\right]
$$

\subsection{Overall comments}

We see that all the factors contribute significantly to the surge in damaged permeability for a composite specimen under loading. The simulation results 


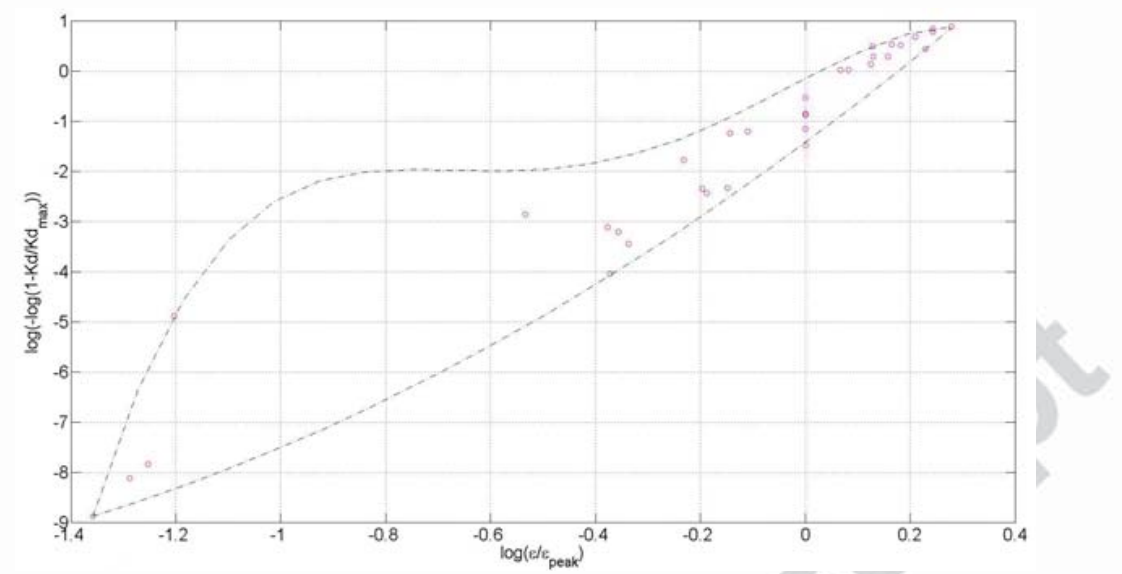

Figure 23: Modified higher-order Avrami bounding curves generated by the convex hull, unacceptable due to the non monotonic evolution

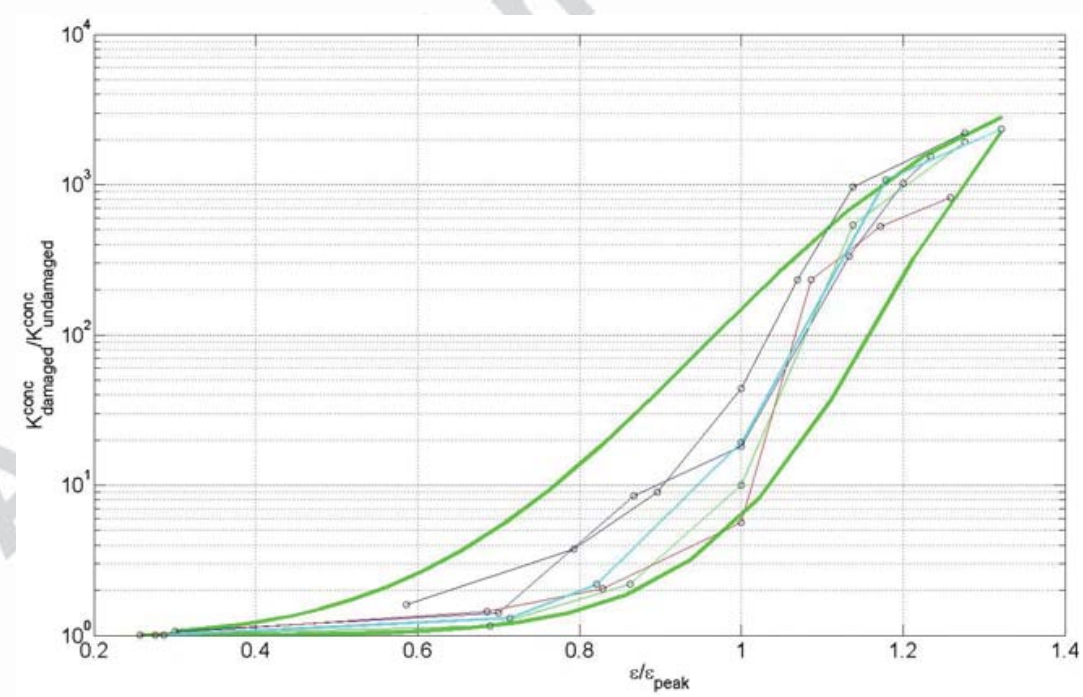

Figure 24: Bounding envelope curves shown with the permeability evolution at different aggregate fractions 
we have obtained, allow us, as we have seen, to define bounding envelope curves for the multiphase composite specimen's permeability with progressive damage under uniaxial compression for an aggregate fractions between $10 \%$ and 30 $\%$. This particular law is clearly valid only for a composite using the same aggregates and mortar phase as we have used in the experimental investigation, but the approach remains the same regardless of the individual details, the number of phases contributing to the different hygro-mechanical phenomena, and of course, the number of experimental points available.

The greater the number of experimental points, the greater the reliability of these envelope bounding curves. In addition, the use of a conforming mesh, while greatly reducing computational effort, could throw in some mesh dependence but cannot completely alter the trend of the curves obtained.

\section{Conclusions}

The transport properties of cementitious composites are important indicators of their durability and are greatly influenced by damage progression during mechanical loading. In this work, we have used our previously developed morphological 3D matrix-inclusion-ITZ model for a cementitious composite at the mesoscale and used this model to perform a series of virtual mechanical tests on a cylindrical composite specimen followed by a permeability calculation to determine mechanical-transport coupling during compressive loading.

We identified the relevant model mechanical and hygral parameters from a single set of experimentally obtained mechanical and permeability results for both the mortar phase as well as the composite. We then subjected a series of virtual composite specimens at different aggregate fractions and granulometric distributions to quasi-static uniaxial compressive loading with varying boundary conditions and damage thresholds, to obtain the simulated damage and strain evolutions, and determined the macroscopic permeability tensor for the specimens using a network model with the simulated damage data and previously identified hygral paramaters. The result of the parameter study is a pair of 
upper and lower bounding curves for the evolution of damaged permeability at different loading points for which we used the Avrami equation.

Some obvious weaknesses of the particular results obtained in this paper, rather than of the protocol itself, are a lack of additional experimental points for the composite on both sides of the loading curve, as well as the use of a conforming mesh instead of a non conforming mesh to reduce computational effort. These weaknesses do not in any way alter the methodology of the protocol or its application to cementitious and other damageable composite materials in general. A clear extension of both the principles as well as the network model used here is the mesoscale investigation of chloride diffusion during damage progression under mechanical loading. One may eventually use portions of the approach to model other durability indicators such as carbonation and potentially lixiviation at the microscale, under degradation due to loading.

[1] S. Kamali-Bernard, F. Bernard, Effect of tensile cracking on diffusivity of mortar: 3d numerical modelling, Computational Materials Science 47 (1) (2009) $178-185$.

[2] M. Alexander, A. Bertron, N. De Belie, Performance of Cement-Based Materials in Aggressive Aqueous Environments: State-of-the-Art Report, RILEM TC 211 - PAE, RILEM State-of-the-Art Reports, Springer Netherlands, 2012

URL https://books .google.fr/books?id=IbvF4r7RoAYC

[3] E. Roziere, A. Loukili, R. E. Hachem, F. Grondin, Durability of concrete exposed to leaching and external sulphate attacks, Cement and Concrete Research 39 (12) (2009) 1188-1198.

[4] M. Choinska, A. Khelidj, G. Chatzigeorgiou, G. Pijaudier-Cabot, Effects and interactions of temperature and stress-level related damage on permeability of concrete, Cement and Concrete Research 37 (1) (2007) 79 88. 
[5] H. R. Samaha, K. C. Hover, Influence of microcracking on the mass transport properties of concrete, ACI Materials Journal 89 (4) (1992) 416-424.

[6] V. Picandet, A. Khelidj, G. Bastian, Effect of axial compressive damage on gas permeability of ordinary and high-performance concrete, Cement and Concrete Research 31 (11) (2001) 1525 - 1532.

[7] C. Lim, N. Gowripalan, V. Sirivivatnanon, Microcracking and chloride permeability of concrete under uniaxial compression, Cement and Concrete Composites 22 (5) (2000) $353-360$.

[8] M. Saito, H. Ishimori, Chloride permeability of concrete under static and repeated compressive loading, Cement and Concrete Research 25 (4) (1995) $803-808$

[9] V. Picandet, A. Khelidj, H. Bellegou, Crack effects on gas and water permeability of concretes, Cement and Concrete Research 39 (6) (2009) 537 547 .

[10] A. D. Tegguer, S. Bonnet, A. Khelidj, V. Baroghel-Bouny, Effect of uniaxial compressive loading on gas permeability and chloride diffusion coefficient of concrete and their relationship, Cement and Concrete Research 52 (2013) $131-139$.

[11] G. Pijaudier-Cabot, F. Dufour, M. Choinska, Permeability due to the increase of damage in concrete: From diffuse to localized damage distributions, Journal of Engineering Mechanics 135 (9) (2009) 1022-1028.

[12] G. Chatzigeorgiou, V. Picandet, A. Khelidj, G. Pijaudier-Cabot, Coupling between progressive damage and permeability of concrete: analysis with a discrete model, International Journal for Numerical and Analytical Methods in Geomechanics 29 (10) (2005) 1005-1018.

[13] X. Jourdain, J.-B. Colliat, C. DeSa, F. Benboudjema, F. Gatuingt, Upscaling permeability for fractured concrete: mesomacro numerical approach 
coupled to strong discontinuities, International Journal for Numerical and Analytical Methods in Geomechanics 38 (5) (2014) 536-550.

[14] K. Nagai, Y. Sato, T. Ueda, Mesoscopic simulation of failure of mortar and concrete by $3 \mathrm{~d}$ rbsm, Journal of Advanced Concrete Technology 3 (3) (2005) $385-402$

[15] R. Pedersen, A. Simone, L. Sluys, Mesoscopic modeling and simulation of the dynamic tensile behavior of concrete, Cement and Concrete Research $50(0)(2013) 74-87$.

[16] P. A. Bhat, N. Debnath, Theoretical and experimental study of structures and properties of cement paste: The nanostructural aspects of csh, Journal of Physics and Chemistry of Solids 72 (8) (2011) 920-933.

[17] F. Grondin, M. Matallah, How to consider the interfacial transition zones in the finite element modelling of concrete?, Cement and Concrete Research 58 (2014) $67-75$.

[18] E. Schlangen, E. Garboczi, Fracture simulations of concrete using lattice models: Computational aspects, Engineering Fracture Mechanics 57 (23) (1997) $319-332$.

[19] G. Cusatis, Z. Bazant, L. Cedolin, Confinement-shear lattice model for concrete damage in tension and compression: Ii. computation and validation, ASCE Journal of Engineering Mechanics 129 (12) (2003) 1449 - 1458.

[20] I. Belova, G. Murch, Diffusion in nanocrystalline materials, Journal of Physics and Chemistry of Solids 64 (5) (2003) $873-878$.

[21] Y. Yang, Z. Li, C. Neo, J. Ding, Model design on calculations of microwave permeability and permittivity of fe/sio2 particles with core/shell structure, Journal of Physics and Chemistry of Solids 75 (2) (2014) 230 - 235.

[22] R. Barretta, R. Luciano, Exact solutions of isotropic viscoelastic functionally graded kirchhoff plates, Composite Structures 118 (2014) 448 - 454. 
[23] A. Apuzzo, R. Barretta, R. Luciano, Some analytical solutions of functionally graded kirchhoff plates, Composites Part B: Engineering 68 (2015) 266 -269 .

[24] S. Kamali-Bernard, D. Keinde, F. Bernard, Effect of aggregate type on the concrete matrix/aggregates interface and its influence on the overall mechanical behavior. a numerical study, Key Engineering Materials 617 (2014) $14-17$.

[25] D. Keinde, F. Bernard, S. Kamali-Bernard, Effect of the interfacial transition zone and the nature of the matrix-aggregate interface on the overall elastic and inelastic behaviour of concrete under compression: a $3 \mathrm{~d} n u-$ merical study, European Journal of Environmental and Civil Engineering 18 (10) (2014) $1167-1176$.

[26] D. Niknezhad, B. Raghavan, F. Bernard, S. Kamali-Bernard, Towards a realistic morphological model for the meso-scale mechanical and transport behavior of cementitious composites, Composites Part B: Engineering 81 (2015) $72-83$.

[27] H. Zhao, W. Sun, X. Wu, B. Gao, The effect of coarse aggregate gradation on the properties of self-compacting concrete, Materials \& Design 40 (0) (2012) $109-116$.

[28] J. G. Jawahar, C. Sashidhar, I. R. Reddy, J. A. Peter, Effect of coarse aggregate blending on short-term mechanical properties of self compacting concrete, Materials \& Design 43 (0) (2013) 185 - 194.

[29] I. Nikbin, M. Beygi, M. Kazemi, J. V. Amiri, E. Rahmani, S. Rabbanifar, M. Eslami, A comprehensive investigation into the effect of aging and coarse aggregate size and volume on mechanical properties of self-compacting concrete, Materials \& Design 59 (0) (2014) 199 - 210.

[30] P. Wriggers, S. Moftah, Mesoscale models for concrete: Homogenisation 
and damage behaviour, Finite Elements in Analysis and Design 42 (7) (2006) $623-636$.

[31] Y. B. Zaitsev, F. Wittmann, Simulation of crack propagation and failure of concrete, Matriaux et Constructions 14 (5) (1981) 357 - 365.

[32] J. Saliba, F. Grondin, M. Matallah, A. Loukili, H. Boussa, Relevance of a mesoscopic modeling for the coupling between creep and damage in concrete, Mechanics of Time-Dependent Materials 17 (3) (2013) 481-499.

[33] F. Bernard, S. Kamali-Bernard, W. Prince, 3d multi-scale modelling of mechanical behaviour of sound and leached mortar, Cement and Concrete Research 38 (4) (2008) 449 - 458.

[34] I. Comby-Peyrot, F. Bernard, P.-O. Bouchard, F. Bay, E. Garcia-Diaz, Development and validation of a $3 \mathrm{~d}$ computational tool to describe concrete behaviour at mesoscale. application to the alkali-silica reaction, Computational Materials Science 46 (4) (2009) 1163 - 1177.

[35] Z. Qian, E. Garboczi, G. Ye, E. Schlangen, Anm: a geometrical model for the composite structure of mortar and concrete using real-shape particles, Materials and Structures (2014) 1-10.

[36] A. Ibrahimbegovic, A. Delaplace, Microscale and mesoscale discrete models for dynamic fracture of structures built of brittle material, Computers \& Structures 81 (12) (2003) 1255 - 1265.

[37] T. I. Zohdi, P. Wriggers, Aspects of the computational testing of the mechanical properties of microheterogeneous material samples, International Journal for Numerical Methods in Engineering 50 (11) (1981) 2573 - 2599.

[38] G. Ye, P. Lura, K. van Breugel, Modelling of water permeability in cementitious materials, Materials and Structures 39 (9) (2006) 877-885.

[39] J. F. Sima, P. Roca, C. Molins, Cyclic constitutive model for concrete, Engineering Structures 30 (3) (2008) 695 - 706. 
[40] M. Villar, P. Martin, F. Romero, J. Barcala, Results of the tests on concrete (part 2), forge report, Tech. Rep. D3.16 (2012).

[41] M. Villar, V. Gutierrez-Rodrigo, P. Martin, F. Romero, J. Barcala, Results of the tests on bentonite (part 2), ciemat technical report, Tech. Rep. CIEMAT/DMA/2G207/07/12 (2012).

[42] MATLAB, version 7.10.0 (R2010a), The MathWorks Inc., Natick, Massachusetts, 2010.

[43] L. M. Kachanov, O vremeni razrusenija v usloviach polzucesti, Izv. Akad. Nauk CCCP, Otd. Techn. Nauk 8 (1958) $26-31$.

[44] Y. N. Rabotnov, Creep problems in structural members, ZAMM - Journal of Applied Mathematics and Mechanics / Zeitschrift fur Angewandte Mathematik und Mechanik 51 (7) (1971) 575-576.

[45] T. Jankowiak, T. Lodygowski, Identification of parameters of concrete damage plasticity constitutive model, Foundations of Civil and Environmental Engineering 16 (2005) 53-69.

[46] J. Mazars, A description of micro- and macroscale damage of concrete structures, Engineering Fracture Mechanics 25 (5) (1986) 729 - 737.

[47] J. Mazars, Continuum damage theoryapplication to concrete, Journal of Engineering Mechanics 115 (2) (1989) 345-365.

[48] J. Mazars, G. Pijaudier-Cabot, From damage to fracture mechanics and conversely: A combined approach, International Journal of Solids and Structures 33 (2022) (1996) 3327 - 3342.

[49] M. T. van Genuchten, A closed-form equation for predicting the hydraulic conductivity of unsaturated soils, Soil Science Society of America Journal 44 (5) (1980) 892-898.

[50] M. Janz, Moisture transport and fixation in porous materials at high moisture levels, Ph.D. thesis, Lund University (2000). 
[51] B. Nayroles, G. Touzot, P. Villon, Generalizing the finite element method: Diffuse approximation and diffuse elements, Computational Mechanics 10 (5) (1992) 307-318.

[52] L. Xia, B. Raghavan, P. Breitkopf, W. Zhang, Numerical material representation using proper orthogonal decomposition and diffuse approximation, Applied Mathematics and Computation 224 (0) (2013) 450 - 462.

[53] B. Raghavan, G. Le Quilliec, P. Breitkopf, A. Rassineux, J.-M. Roelandt, P. Villon, Numerical assessment of springback for the deep drawing process by level set interpolation using shape manifolds, International Journal of Material Forming 7 (4) (2014) 487-501.

[54] F. Bernard, S. Kamali-Bernard, Numerical study of $\{$ ITZ $\}$ contribution on mechanical behavior and diffusivity of mortars, Computational Materials Science 102 (0) (2015) $250-257$.

[55] P. R. Rangaraju, J. Olek, S. Diamond, An investigation into the influence of inter-aggregate spacing and the extent of the $\{$ ITZ $\}$ on properties of portland cement concretes, Cement and Concrete Research 40 (11) (2010) $1601-1608$.

[56] C. Geuzaine, J.-F. Remacle, Gmsh: A 3-d finite element mesh generator with built-in pre- and post-processing facilities, International Journal for Numerical Methods in Engineering 79 (11) (2009) 1309-1331.

[57] C. C. Yang, R. Huang, W. Yeih, I. C. Sue, Aggregate effect on elastic moduli of cement-based composite materials, Journal of Marine Science and Technology 3 (1) (1995) $5-10$.

[58] J. A. Nelder, R. Mead, A simplex method for function minimization, The Computer Journal 7 (4) (1965) 308-313. doi:10.1093/comjnl/7.4.308.

[59] M. Avrami, Kinetics of phase change. i general theory, Journal of Chemical Physics 7 (1939) 1103-1112. 
[60] A. N. Kolmogorov, On the statistical theory of metal crystallization, Izv. Akad. Nauk SSSR, Ser. Math 1 (1937) 335-360.

[61] K. Mori, T. Fukunaga, M. Sugiyama, K. Iwase, K. Oishi, O. Yamamuro, Hydration properties and compressive strength development of low heat cement, Journal of Physics and Chemistry of Solids 73 (11) (2012) $1274-$ 1277 . 